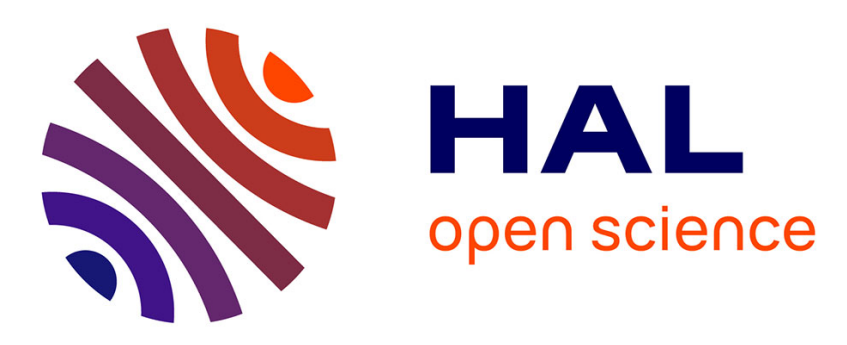

\title{
Homogeneous Supported Monolayer from Microbial Glycolipid Biosurfactant
}

\author{
Niki Baccile, Anyssa Derj, Cedric Boissiere, Vincent Humblot, Ariane
}

Deniset-Besseau

\section{To cite this version:}

Niki Baccile, Anyssa Derj, Cedric Boissiere, Vincent Humblot, Ariane Deniset-Besseau. Homogeneous Supported Monolayer from Microbial Glycolipid Biosurfactant. Journal of Molecular Liquids, 2022, 345 (117827), 10.1016/j.molliq.2021.117827 . hal-03149331

\section{HAL Id: hal-03149331 \\ https://hal.science/hal-03149331}

Submitted on 20 Oct 2021

HAL is a multi-disciplinary open access archive for the deposit and dissemination of scientific research documents, whether they are published or not. The documents may come from teaching and research institutions in France or abroad, or from public or private research centers.
L'archive ouverte pluridisciplinaire HAL, est destinée au dépôt et à la diffusion de documents scientifiques de niveau recherche, publiés ou non, émanant des établissements d'enseignement et de recherche français ou étrangers, des laboratoires publics ou privés. 


\section{Homogeneous Supported Monolayer from Microbial Glycolipid Biosurfactant}

Niki Baccile, ${ }^{\mathrm{a},{ }^{*}}$ Anyssa Derj, ${ }^{\mathrm{a}}$ Cédric Boissière, ${ }^{\mathrm{a}}$ Vincent Humblot, ${ }^{\mathrm{b}, \mathrm{c}}$ Ariane Deniset-Besseau ${ }^{\mathrm{d}}$

${ }^{\text {a }}$ Sorbonne Université, Centre National de la Recherche Scientifique, Laboratoire de Chimie de la Matière Condensée de Paris, LCMCP, F-75005 Paris, France

${ }^{\mathrm{b}}$ Sorbonne Université, Laboratoire de Réactivité de Surface (LRS), UMR CNRS 7197, 4 place Jussieu, Paris, F-75005, France

${ }^{c}$ Current address : FEMTO-ST Institute, UMR CNRS 6174, Université Bourgogne FrancheComté, 15B avenue des Montboucons, 25030 Besançon Cedex, France

${ }^{\mathrm{d}}$ Université Paris-Saclay, CNRS, Institut de Chimie Physique, UMR 8000, 91405, Orsay, France

\section{* Corresponding author:}

Dr. Niki Baccile

E-mail address: niki.baccile@ sorbonne-universite.fr

Phone: +331442756 77 


\begin{abstract}
The development of supported glycosylated lipid layers is an important trend in the field of glyconanomaterials for their interest in understanding sugar-sugar and protein-sugar interactions, these being at the core of cellular, bacterial or viral adhesion. The conventional self-assembled monolayer (SAM) approach generally requires a thiolated glycoconjugate and a gold substrate. In this work, we show how glycolipid amphiphiles of natural origin, commonly known as microbial biosurfactants, can be easily deposited onto a substrate. Spontaneously produced by microorganisms but lacking a thiol group, one can take advantage of their selfassembly properties to prepare homogeneous supported lipid monolayers (SLM). We then choose a saturated glucolipid, G-C18:0, which forms a colloidal lamellar phase under diluted conditions. The lamellae can then be deposited onto a substrate (silicon, gold) using a physical method (dip coating). Dip coating is preferred over more classical deposition methods (Langmuir-Blodgett-LB-, vesicle fusion or spin-coating) because of its versatility, compatibility with aqueous solutions and robust control of the thickness below $10 \mathrm{~nm}$. Defectfree glycosylated SLM from a microbial biosurfactant are then easily developed. A combination of ellipsometry, fluorescence microscopy, atomic force microscopy and infrared nanospectroscopy (AFMIR) show that the glycosylated SLM are defect-free, have a thickness of $2.8 \pm 1.0 \mathrm{~nm}$ and they are highly homogeneous at scales going from the $\mathrm{nm}$ to $\mathrm{cm}$.
\end{abstract}

Keywords: supported lipid bilayers; microbial glycolipids; microbial biosurfactants; dipcoating

\title{
Introduction
}

Glycoconjugates constitute a broad family of sugar-based lipids, which combine chemical functionality, lipid self-assembly and the properties of carbohydrates. ${ }^{1}$ Association of glycoconjugates to nanoscience contributed to develop the field of multidimensional glyconanomaterials like vesicles, ${ }^{2}$ nanoparticles ${ }^{3}$ or functional surfaces. ${ }^{4}$ Interesting for their hydration, ${ }^{5}$ interactions against lectins ${ }^{6-8}$ or between carbohydrates themselves, ${ }^{9}$ twodimensional, supported, glyconanomaterials have found a specific interest for their tunable adhesive, ${ }^{4}$ anti-adhesive ${ }^{1,10}$ and antimicrobial properties ${ }^{11,12}$ but also to better understand virus binding mechanisms. ${ }^{13}$ Glycosylated surfaces are generally prepared by a classical selfassembled monolayer (SAM) process, involving chemisorption of thiolated glycoconjugates onto gold. ${ }^{3,4,10,11}$ However, this approach naturally requires the use of a gold support and tailormade glycoconjugates, of which the synthesis, involving tedious multiple chemical steps typical 
in the chemistry of sugars, is cumbersome and of which the complexity may prevent transferring the applications to larger scales and into devices. It could then be attractive to prepare glycosylated monolayers from ready-made glycoconjugates.

Microbial amphiphiles, known as biosurfactants, are produced by the fermentation of specific yeasts, or bacteria, in the presence of fatty acids and glucose. ${ }^{14,15}$ Natural glycoconjugates due the presence of a freely accessible $\mathrm{COOH}$ group, microbial biosurfactants constitute an interesting biobased source to prepare 2D glyconanomaterials. However, unless specifically modified, as previously done for sophorolipids, ${ }^{11,12,16}$ microbial biosurfactants do not have a thiol group, making the formation of SAM quite difficult. Worst, not all biosurfactants (e.g., surfactin) have a chemically-active group in their molecular structure, thus making derivatization of a thiol conjugate a harsh task of its own. However, their rich phase behaviour in bulk water, ${ }^{17-22}$ combined with a physical deposition method, could be exploited to prepare 2D glyconanomaterials in the form of supported lipid bilayers (SLB).

Since the work of Tamm, ${ }^{23}$ SLB have generated a wide interest across disciplines. Initially proposed as model systems to understand the behavior of biological lipid membranes ${ }^{24}$ ${ }^{26}$ and their interactions with proteins and surfactants, ${ }^{27,28}$ they have recently stimulated new branches of research in materials' science. ${ }^{26,29}$ In the field of nanotechnology for instance, it was shown that SLB are interesting supports to control the epitaxial growth in inorganic nanomembranes, like $\mathrm{ZnO},{ }^{30}$ while in the field of biomedical engineering, they are highlydemanded microscale environments for cell adhesion, proliferation, and differentiation. ${ }^{31-33}$ SLB are also highly demanded to understand the interactions between nanocolloids like particles $^{34}$ or viruses ${ }^{13,35}$ and model lipid membranes.

Preparation of SLB by mean of well-established physical methods does not require the use of functional lipids and the variety of supports is broader. Langmuir-Blodgett (LB) $)^{23,24,36}$ and vesicle fusion ${ }^{25,37-43}$ are by far the most recurrent ones but other methods like drop casting, ${ }^{44}$ spin coating ${ }^{45-50}$ or knife coating ${ }^{51}$ have been developed in the past two decades. Unfortunately, some of these methods are not easy to setup and in many cases achieving large-scale homogeneity of the thickness using physical methods is not guaranteed. Most of them require solubilization of the lipid in a solvent (vesicle fusion, spin coating or knife coating), the use of a specific apparatus (Langmuir trough in LB) or provide multilamellar thick films (drop casting). When the physical properties (e.g., melting temperature, phase diagram, solubility) of the lipid are well-known, as for many phospholipids, LB and vesicle fusion can provide good quality $\mathrm{SLB},{ }^{24}$ but in most cases, solvent evaporation (vesicle fusion) or strong mechanical solicitations (spin coating), generate cracks and poor homogeneity. ${ }^{24,25,50,36,38,41,42,46-49}$ 
Since neither the physical nor the interface properties of microbial biosurfactants are as well known as for phospholipids,${ }^{52}$ most of the physical methods above could generate inhomogeneous SLB. For this reason, we employ dip coating, an evaporation-induced process generally employed in the synthesis of inorganic coatings, ${ }^{54}$ but having multiple advantages over the above-mentioned conventional methods: 1) it can be used with both aqueous solutions and colloidal dispersions; 2) coating thickness and homogeneity can be tuned during the dipping process through the dipping rate, humidity and temperature; 3 ) it was shown to form sub-10 nm coatings. ${ }^{54}$

Previously adopted to deposit another well-known biosurfactant, sophropolipids, onto gold, silicon and titania substrates,${ }^{53}$ we found that coatings were structured but still poorly homogeneous. That finding was attributed to the impact of surface energy to the surface assembly of sophorolipids. For this reason, we employ here another microbial glycolipid amphiphile, the acidic C18:0 glucolipid biosurfactant (G-C18:0, Figure 1a), derived from the fermentation of the yeast $S$. bombicola $\triangle u g t B 1 .{ }^{55} \mathrm{G}-\mathrm{C} 18: 0$ is more atypical than sophorolipids, as in the neutral-acidic $\mathrm{pH}$ range, it forms a stable colloidal dispersion of flat lamellae in water (Figure 1b), instead of micelles. ${ }^{20,21}$ Our strategy then consists in dipping a given substrate (silicon or gold) into a colloidal solution of pre-formed lipid lamellae.

A combination of ellipsometry, optical microscopy, atomic force microscopy (AFM) and infrared nanospectroscopy (AFMIR) shows that a colloidal dispersion of lamellae composed of G-C18:0 can be deposited onto a silicon and gold substrate. The supported 2D glyconanomaterial has a sub-10 $\mathrm{nm}$ thickness and homogeneity from the $\mathrm{nm}$ - to the $\mathrm{cm}$-scale in the substrate plane. Considering the relatively poor knowledge concerning the behavior of microbial biosurfactants are solid-air interfaces, ${ }^{52}$ this work could certainly open new perspectives for this class of amphiphiles. 


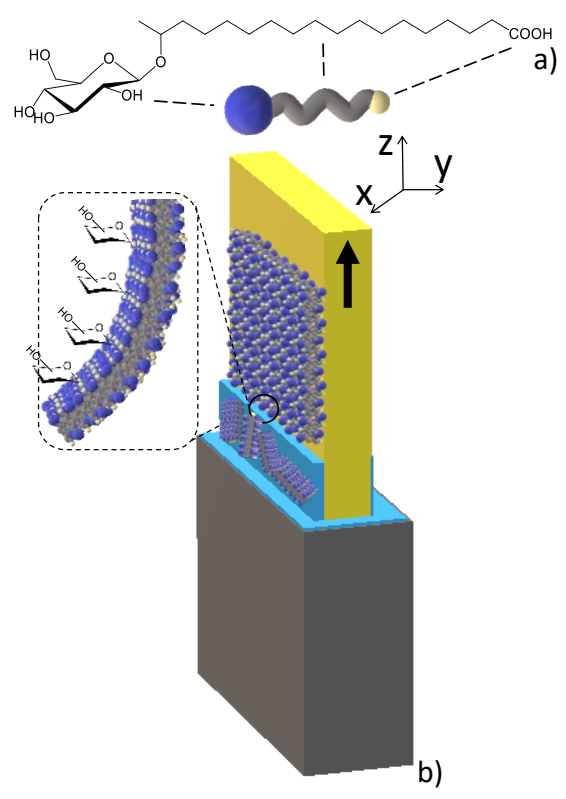

Figure 1 - a) Chemical structure of the microbial glucolipid G-C18:0, Schematic representation of G-C18:0, blue sphere: glucose, grey tail: C18:0 chain, yellow sphere, COOH. b) Scheme of the dip-coating process employed to prepare glycosylated SLM from an aqueous colloidal dispersion of self-assembled interdigitated G-C18:0 lamellae at $\mathrm{C}<1 \mathrm{wt} \%$.

\section{Experimental section}

The experimental section is given in the Supporting Information.

\section{Results and discussion}

G-C18:0 microbial glucolipids (Figure 1a) are insoluble in water below pH 7, when they self-assemble into a lamellar phase between $0.1 \mathrm{wt} \%$ and $10 \mathrm{wt} \% .^{20,21,56,57}$ At concentrations below $1 \mathrm{wt} \%$, the corresponding aqueous solution is composed of colloidally-stable infinitely flat membranes, of thickness about $3.6 \mathrm{~nm}$, as determined by cryo-TEM and small angle X-ray scattering. ${ }^{20,21}$ The thickness corresponds to the typical length of a single G-C18:0 molecule, thus suggesting that the lamellae are interdigitated monolayers, as sketched in Figure 1b. This is not unexpected, because G-C18:0 has a bolaform shape and interdigitation in bolaform monolayer membranes was addressed before. ${ }^{58}$ Even if the monolayer organization of G-C18:0 membranes could recall the structure of SAM, the method to prepare coatings from G-C18:0 membranes and the lack of specific interactions with the support (e.g., thiol-gold, as found in SAM) makes this work conceptually closer to the field of SLB. In the following, we will then use the acronym SLB, when referring to specific literature studies in this field, and the acronym SLM, when referring to the synthesis of supported lipid monolayers prepared from the 
microbial G-C18:0 glucolipid throughout the present study.

If any of the classical methods employed to prepare SLB could be employed, none of them is ideal to prepare SLM from G-C18:0. The conditions to form a self-assembled G-C18:0 monolayer at the air-water interface were never studied and its solubility was never studied either, thus making the LB and spin coating approaches not straightforward. In a previous study, we have observed that G-C18:0 can partially form vesicles above $70^{\circ} \mathrm{C}$, but, first of all, this observation was not quantitative, and, secondly, controlling the conditions for a homogeneous coating at such temperature can be challenging. For this reason, the vesicle fusion approach to prepare SLM is poorly advisable here. Finally, the drop-casting could be an interesting method and it was used before on this systems to measure short-range hydration forces, ${ }^{59}$ but only multilamellar coatings were obtained. For these reasons, we employ an evaporation induced coating method employed here in a vertical dip-coating geometry, never reported before within the frame of SLB.

The use of dip-coating under controlled conditions of temperature, relative humidity and withdrawal rate is fully justified by the possibility to deposit a homogeneous coating using aqueous solution on either $\mathrm{Si}$ wafers or $\mathrm{Au}$ substrates, both being poorly wet by water (contact angle is $69^{\circ} \pm 4^{\circ}$ for $\mathrm{Au}$ and $43^{\circ} \pm 4^{\circ}$ for $\mathrm{Si}$ ). ${ }^{53}$ The dip-coating apparatus employed in this work allows controlling the humidity and temperature in the dip-coating chamber as well as the dip coating rate between $10^{-3}$ and $10 \mathrm{~mm} / \mathrm{s}$. This was demonstrated to be a range broad enough to span from the capillarity to the draining regimes, providing highly homogeneous thin films with thickness, $T_{h}$, varying from 10 to $10^{3} \mathrm{~nm} .{ }^{54} T_{h}$ is measured with ellipsometry, a fast-screening, $m m$-scale, probe with $\AA$-resolution even below $10 \mathrm{~nm}$, if the boundaries of the refractive index are defined with caution (please refer to the Supporting Information for a detailed discussion on the fitting strategy). ${ }^{39}$ A description of the technique, as well as the models and strategy chosen in this work to fit the amplitude $\Psi(\lambda)$ and phase difference $\Delta(\lambda)$ and to extract the sample thickness and refractive index (RI), are described in more detail on P. S3-S5 in the Supporting Information with reference to Figure S 2a, Table S 1 (for Si wafer) and Figure S 3a, Table S 2 (for Au substrates) in the same document.

Two glucolipid G-C18:0 solutions at pH of 9 and 6 are deposited by dip-coating on silicon wafers, employing the dip-coating apparatus described in Figure S 1. This apparatus is developed for the deposition of high-quality thin films with control of temperature, $T$, and relative humidity, $\mathrm{RH} \%$. The entire set of data collected throughout this study is provided in Table S 3, of which a reasoned overview is given in Figure 2 and Figure S 4, discussed hereafter. To prove the formation of a SLM, one should only consider measured thickness values between 
$2 \mathrm{~nm}$ and $10 \mathrm{~nm}$ within the frame of the Cauchy fitting model, whereas optimum values are expected to be between $3 \mathrm{~nm}$ and $5 \mathrm{~nm}$. It was previously shown that withdrawal rate has a huge impact on the film thickness in water, ${ }^{54}$ and for this reason this is the first parameter tested here.

Figure $2 \mathrm{a}$ and Figure $2 \mathrm{c}$ show the evolution of the lipid film thickness as a function of the dip-coating rate, varied between 0.02 and $10 \mathrm{~mm} / \mathrm{s}$. The minimum, around $3 \mathrm{~nm}$, and the maximum, around $100 \mathrm{~nm}$, thickness values are systematically recorded, respectively, around $S_{w}$ of $0.1 \mathrm{~mm} / \mathrm{s}$ and $10 \mathrm{~mm} / \mathrm{s}$, independently from the $\mathrm{pH}$ value, temperature or relative humidity. This is in good agreement with the data reported for inorganic oxides, for which it was shown that the smallest thickness is generally obtained with $S_{w}$ in the order of $0.1 \mathrm{~mm} / \mathrm{s}$. In the water on silicon system, the rate of $0.1 \mathrm{~mm} / \mathrm{s}$ corresponds to the interval between the lowspeed, capillary, and high-speed, draining, regimes, where thickness is minimized. ${ }^{54}$ All samples prepared at low $S_{w}$ are of good quality (red circles in Figure 2a,c) and display a homogeneous thickness on at least $5 \%$ of the coated surface. This is estimated by combining the quality of the fit (for a typical good quality fit please refer to Figure $S 2 b$ ) and the surface probed by the beam (beam size is between $0.15 \mathrm{~cm}^{2}$ and $0.20 \mathrm{~cm}^{2}$, to be compared with a coating of about $3 \mathrm{~cm}^{2}$ ). Selected samples have been analyzed on three different spots without any obvious change in the $\Psi(\lambda)$ and $\Delta(\lambda)$ spectra, thus indicating a homogeneity on at least $15 \%$ of the total surface, suggesting a $\mathrm{cm}$-scale homogeneity of the coating. At higher $S_{w}$, the samples are thicker and inhomogeneous, and of overall poorer quality, as indicated by the green and blue colored circles in Figure 2a,c. In the following, we will only discuss the most homogeneous samples obtained with $0.055<S_{w} / \mathrm{mm} / \mathrm{s}<0.2$. 

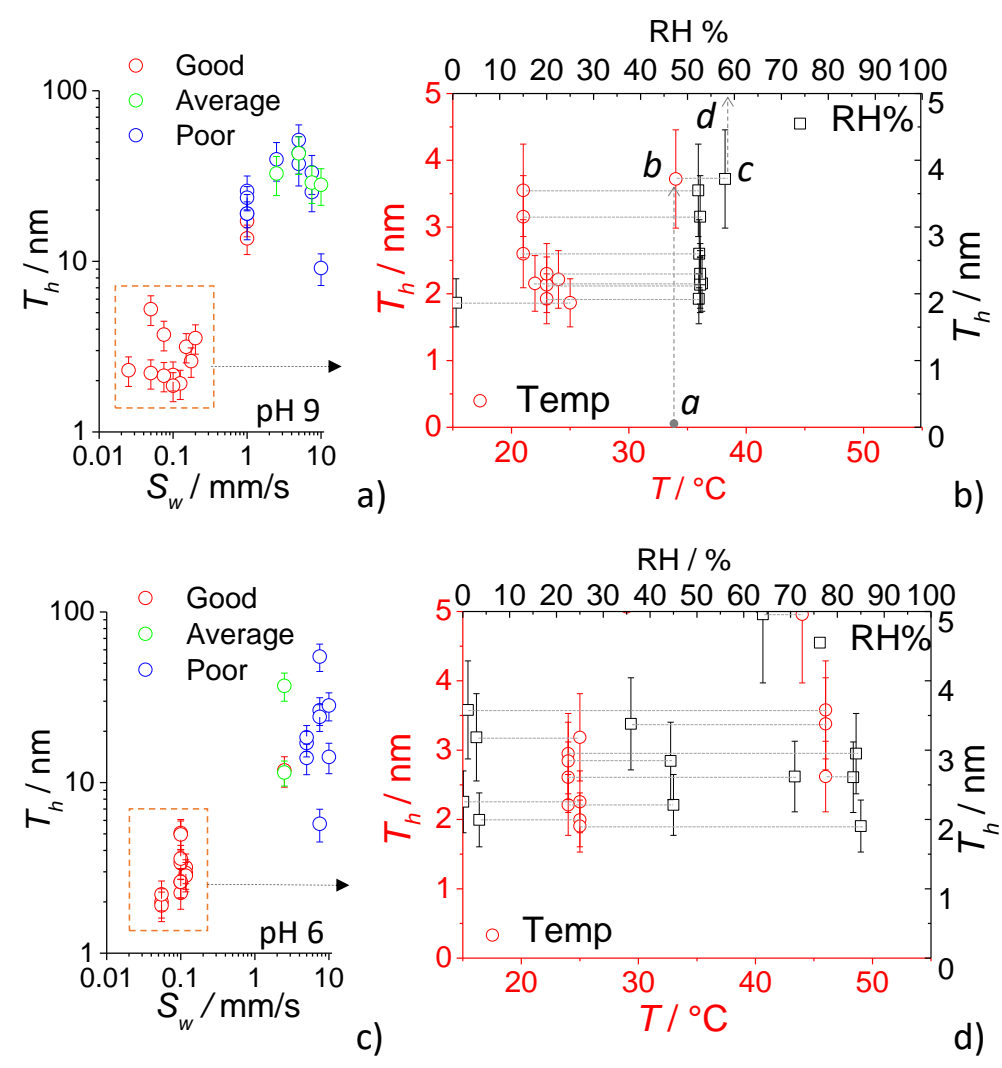

Figure 2 - Thickness, $T_{h}$, of the dip-coated G-C18:0 lipid film measured by ellipsometry as a function of temperature, $T$, withdrawal rate, $S_{w}$, and relative humidity, $R H \%$ and prepared from a lipid solution at $C_{\mathrm{G}}$ C18:0 $=5 \mathrm{mg} / \mathrm{mL}$. a,c) Evolution of $T_{h}$ as a function of $S_{w}$ for lipid solutions prepared at (a) $\mathrm{pH} 9$ (red samples in Table S 3) and (c) pH 6 (green samples in Table $\mathrm{S} \mathrm{3}$ ) for a wide range of $\mathrm{T}\left(23^{\circ} \mathrm{C}-50^{\circ} \mathrm{C}\right)$ and $\mathrm{RH} \%(5 \%$ - 90\%). b-d) Evolution of $T_{h}$ as a function of $\mathrm{RH} \%$ and $T$ for lipid solutions prepared at (b) $\mathrm{pH}=9$ and (d) pH 6 for $S_{w}=0.13 \pm 0.10 \mathrm{~mm} / \mathrm{s}$. In graphs (b) and (d), $T_{h}$ given by red circles (left ordinate, bottom $T$ abscissa) is correlated to $T_{h}$ values given by black squares (right ordinate, top $R H \%$ abscissa) through the dotted grey line. For a given $T$ (e. g., point $a$ on the bottom red abscissa, graph in b)), one reads the corresponding $T_{h}$ (red circle $b$, left red ordinate). Following the horizontal grey line leads to point $c$ (black square, right ordinate), of which the corresponding $R H \%$ is given by the top black abscissa (point $d$ ).

The second parameter of major importance is the lipid concentration in the parent solution. Figure $\mathrm{S} 4 \mathrm{a}$ shows the evolution of $T_{h}$ at three lipid concentrations $(1,3$ and $5 \mathrm{mg} / \mathrm{mL})$ in the parent solution at $\mathrm{pH}$ 6. All corresponding $\Psi(\lambda)$ and $\Delta(\lambda)$ spectra can be satisfactorily fitted (Table S 3) and one finds that concentrations below $5 \mathrm{mg} / \mathrm{mL}$, independently from the temperature and relative humidity, provide lipid coatings of thickness being significantly less than $2 \mathrm{~nm}$, which is not a physically-acceptable result. This could either indicate that the coating does not take place or, most likely, the presence of an inhomogeneous coating. For this reason, most data presented hereafter will mainly concern lipid solutions at concentration of $5 \mathrm{mg} / \mathrm{mL}$, both at acidic and basic $\mathrm{pH}$. 
Relative humidity and temperature are two important parameters, which are known to have a strong impact on the thickness of thin solid films. ${ }^{54}$ Figure $S 4 b$ shows the evolution of $T_{h}$ as a function of $R H \%$ for samples prepared from acidic and basic solutions at $C=5 \mathrm{mg} / \mathrm{mL}$, several withdrawal rates contained in the range, $S_{w}=0.13 \pm 0.10 \mathrm{~mm} / \mathrm{s}$ and a range of temperature between $25^{\circ} \mathrm{C}$ and $50^{\circ} \mathrm{C}$. At acidic $\mathrm{pH}$ (red circles), the thickness is systematically between $2 \mathrm{~nm}$ and $5 \mathrm{~nm}$, independently from the value of $R H \%$. At basic $\mathrm{pH}$, on the contrary, only samples in the range $40<R H \%<70$ show thickness between $2 \mathrm{~nm}$ ad $5 \mathrm{~nm}$, while $T_{h} \leq 2$ $\mathrm{nm}$ for higher and lower $R H \%$. To understand whether or not temperature plays a role, a more precise correlation between $R H \%$ and $T$ is shown on Figure $2 \mathrm{~b}$ and Figure $2 \mathrm{~d}$ (refer to legend of Figure $2 b, d$ for more details in the graph readability) only for those samples in Figure $S 4 b$ having a physically real thickness above $2 \mathrm{~nm}$. At both basic and acidic $\mathrm{pH}$, the values of $T_{h}$ is always contained between $2 \mathrm{~nm}$ and $5 \mathrm{~nm}$ in the range of temperature explored $\left(25^{\circ} \mathrm{C}-45^{\circ} \mathrm{C}\right)$, without any specific trend between room temperature and $45^{\circ} \mathrm{C}$.

In summary, ellipsometry experiments indicate that dipping a solution of G-C18:0 glucolipid $(C=5 \mathrm{mg} / \mathrm{mL}$ ) on a $\mathrm{Si}$ wafer provides homogeneous SLM on the $\mathrm{cm}$-scale and of average thickness, $T_{h}=2.8 \pm 1.0 \mathrm{~nm}$. This result is quite robust, because the error, less than $50 \%$, is calculated over 26 experiments (Figure 2b,d) performed within a broad range of dipping parameters $\left(S_{w}=0.13 \pm 0.10 \mathrm{~mm} / \mathrm{s}, T=30 \pm 10^{\circ} \mathrm{C}\right.$ and $\left.R H \%=55 \pm 10 \%\right)$. If these conditions hold for glucolipid solutions at acidic and basic $\mathrm{pH}$, the impact of relative humidity at acidic $\mathrm{pH}$ seems much more limited, and good quality coating can be obtained in a humidity range between $5 \%$ and $90 \%$. These conditions are also summarized in Table 1, which in fact provides a broader confidence rage of thickness $(2 \mathrm{~nm}-10 \mathrm{~nm})$. This is meant to remind the uncertainty associated to the Cauchy model employed to fit of $\Psi(\lambda)$ and $\Delta(\lambda)$ profiles. This model provides a good description for those samples prepared under the conditions depicted in Table 1 but it probably fails for those experimental conditions providing coating of $T_{h}<2 \mathrm{~nm}$. For this reason, ellipsometry measurements should be coupled to more local probes, which can give a better insight of the coating's homogeneity, composition and possibly thickness at the $\mathrm{mm}$ - and $\mu \mathrm{m}$ scales.

Table 1 - Most suitable experimental conditions to prepare homogeneous G-C18:0 SLM between $2<T_{h} /$ nm $<10$ using a Si wafer substrate estimated by ellipsometry experiments.

\begin{tabular}{|c|c|c|c|c|}
\hline $\mathrm{pH}$ of solution & $\begin{array}{c}\text { Concentration of } \\
\text { solution } / \mathrm{mg} / \mathrm{mL}\end{array}$ & Range of $T_{h} / \mathrm{nm}$ & $\begin{array}{c}\text { Range of } T / \\
{ }^{\circ} \mathrm{C}\end{array}$ & Range of $R H \%$ \\
\hline 6 & 5 & $2-15$ & $20-45$ & $5-90$ \\
\hline 9 & 5 & $2-15$ & $20-40$ & $40-70$ \\
\hline
\end{tabular}


Optical fluorescence microscopy has long been used to study the homogeneity ${ }^{60}$ of SLB on the $m m$-scale as well as their dynamic properties through fluorescence recovery after photobleaching (FRAP). ${ }^{29,60,61}$ Fluorescence microscopy is recorded on two sets of samples, at high and low $S_{w}$. Figure 3a,b shows the typical images of two heterogeneous coatings prepared at $S_{w}=5 \mathrm{~mm} / \mathrm{s}$ at both acidic and basic $\mathrm{pH}$, in agreement with the corresponding ellipsometry data (blue circles in Figure 2a,c). According to ellipsometry, these samples have an average thickness between $10 \mathrm{~nm}$ and $50 \mathrm{~nm}$, which could explain the heterogeneous fluorescence signal. On the contrary, Figure 3c,d show two samples prepared from both acidic and basic solutions at $S_{w}=0.1 \mathrm{~mm} / \mathrm{s}$. In this case, fluorescence microscopy shows a homogeneous image with a poorly contrasted fluorescence signal, making it nearly impossible to determine the presence of the fluorophore and its distribution across the sample. If these images are in agreement with a $\mathrm{mm}$-scale homogeneous distribution of the fluorophore within a sub-10 nm coating, standard and spectroscopic AFM are performed on selected samples prepared at $S_{w}=$ $0.1 \mathrm{~mm} / \mathrm{s}$ to confirm the coating homogeneity and its composition. 


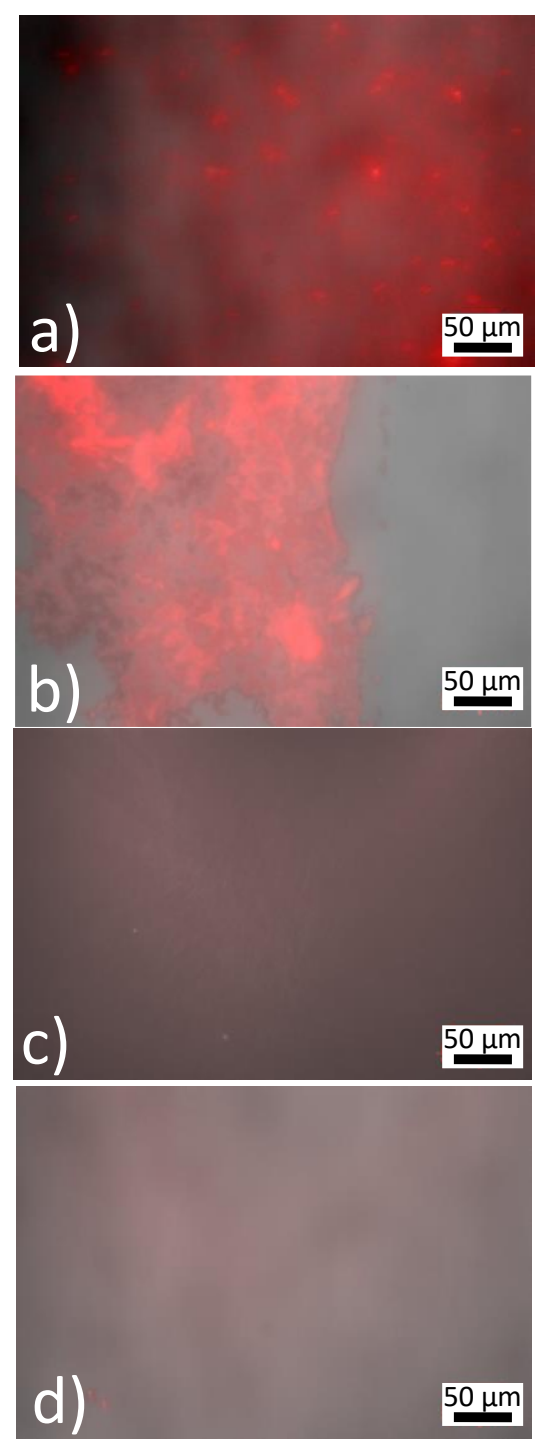

Figure 3 - Fluorescence microscopy experiments performed on G-C18:0 lipid coated silicon substrates. Lipid solutions contain Liss in 200:1 lipid:Liss molar ratio. a) Sample 187 (pH 9) and b) sample 203 (pH 6) are dip-coated at the unfavorable conditions of $S_{w}=5 \mathrm{~mm} / \mathrm{s}$, while c) sample 171 and d) sample 173 are dipcoated at the favorable conditions of $S_{w}=0.1 \mathrm{~mm} / \mathrm{s}$. Sample list is given in Table $\mathrm{S} 3$.

Figure 4 presents the AFM images, and their corresponding height, $h$, profiles, recorded on silicon substrates coated from acidic $(\mathrm{a}, \mathrm{b})$ and basic $(\mathrm{c}, \mathrm{d})$ lipid solutions. Disregarding some typical artifacts like surface contamination (SC) or line streaks (LS), ${ }^{62}$ Figure 4a,c, recorded on $50 \times 50 \mu \mathrm{m}$ and $20 \times 20 \mu \mathrm{m}$ surface areas, show a thoroughly homogeneous surface, closely looking like the control, undipped, silicon substrate (Figure S 5, also containing SC and LS artifacts). No clearly identified edges, multilayers or holes can be observed, as commonly found in classical AFM imaging of SLB. ${ }^{27,36,47,63-66}$ The homogeneity of the samples in Figure 4 compared to the Si wafer control is also demonstrated by the surface roughness $(R)$ parameters, all shown in Table S 4 and related description in the Supporting Information. The height profile 
of the control is given as a reference in Figure S 5a but also superimposed as a red line to the $h(d)$ profiles below Figure 4a,c.
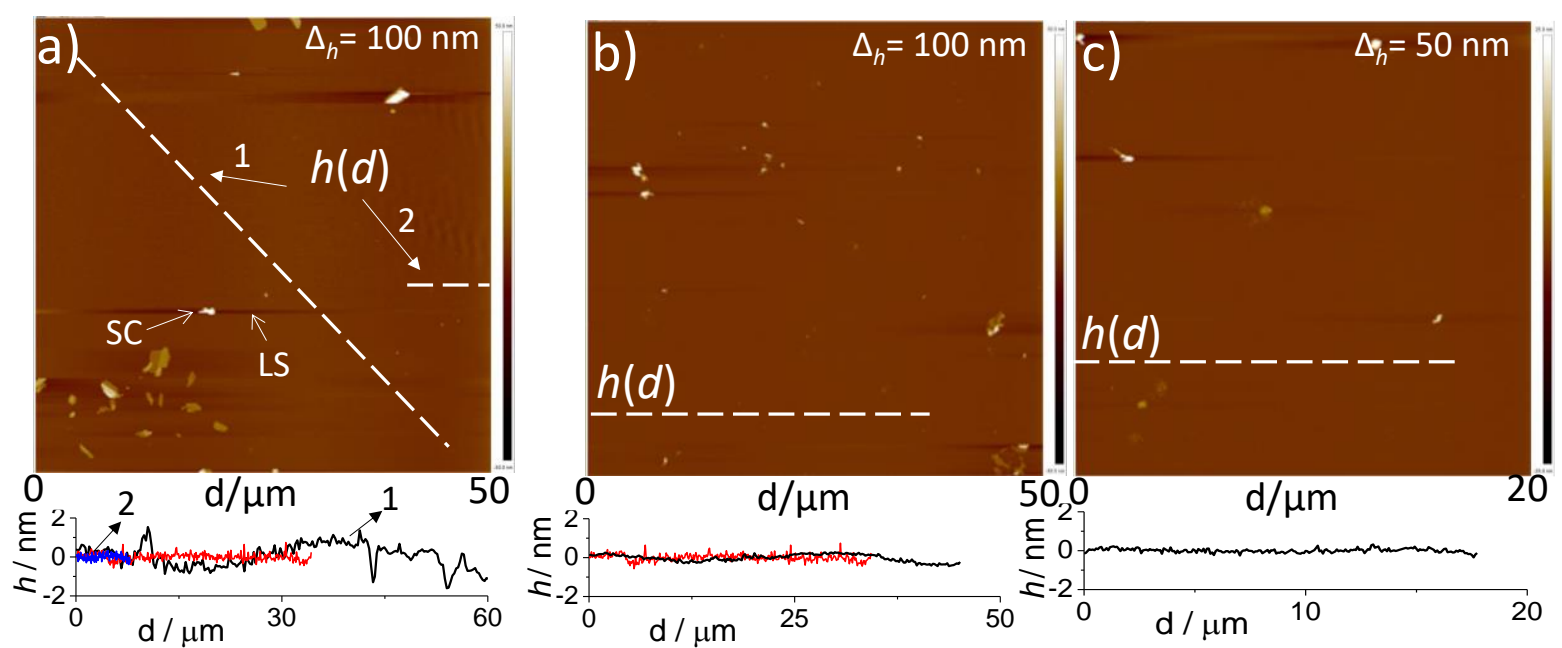

Figure 4 - AFM experiments performed on G-C18:0 lipid coated $\mathrm{Si}$ wafer substrates $\left(S_{w}=0.1 \mathrm{~mm} / \mathrm{s}\right.$ and $R H \%=66 \%$ ). a) Sample 171; b,c) Sample 176. Sample list is given in Table S 3. Height acronyms: $\Delta_{h}=$ peakto-valley thickness on the entire image; $h(d)=$ thickness $v s$. distance profiles are represented by the segmented white line and correspondingly given below each image (black). The red profile in a) and b) corresponds to the bare, control, silicon substrate, shown in Figure S 5a. Artifact acronyms: LS= line streaks; $\mathbf{S C}=$ surface contamination.

The surface roughness analysis shows that: 1) the roughness is less than $1 \mathrm{~nm}$ on distances between 15 and $60 \mu \mathrm{m}$, that is an approximate scale ratio of $\left.1: 10^{5} ; 2\right)$ the roughness in the samples is comparable to the bare silicon wafer. These points quantify the $\mu m$-scale homogeneity of the G-C18:0 lipid coating onto silicon on selected samples of $T_{h}<10 \mathrm{~nm}$; however, they also raise a fundamental question about the actual surface coverage. To prove the presence of single, or even multi, lipid layer(s), AFM requires a clear-cut difference in height between the coating and the substrate. In the case of a thoroughly homogeneous coverage, as shown in Figure 4, it is virtually impossible to confirm the presence of a lipid layer onto the substrate. In addition, all tentative AFM imaging performed on the most homogeneous samples, selected according to ellipsometry and fluorescence microscopy, provide similar images to what we show on Figure 4. Surface scratching is sometimes used as a way to remove the coating to measure its thickness with respect to the scratched background; however, in the case of SLB, it was shown that this approach is not reliable: lipids can be pushed towards the surface, instead of being removed, they can adsorb onto the tip or they can also diffuse back to fill up the hole soon after scratching. ${ }^{65-67}$ To study the coating homogeneity and its composition 
at the same time, we then perform additional spectroscopic experiments combining AFM and infrared spectroscopy.

IR spectroscopy associated to AFM (AFMIR) is a recently-developed technique ${ }^{68}$ allowing local infrared analysis with sub-wavelength spatial resolution ${ }^{69,70}$ and employed for chemical mapping at the nanoscale on a wide range of inorganic, organic and biological systems. ${ }^{71-74}$ In this study, AFMIR experiments are performed on a series of G-C18:0 lipid coated gold substrates, the latter, associated to gold-coated tip, ensuring an enhancement of the local electric field, thus improving the sensitivity of the technique. If the use of gold instead of silicon could induce changes in the surface aggregation of other glycolipids, like sophorolipids, ${ }^{53}$ we exclude major effects, as shown in the Supporting Information (discussion on Page S16-17 in relationship with Figure S 6 and Table S 5 in the same document). Under similar dipping conditions, the use of a gold substrate promote an equally homogenous, although slightly thicker (by a factor about two), lipid coating.
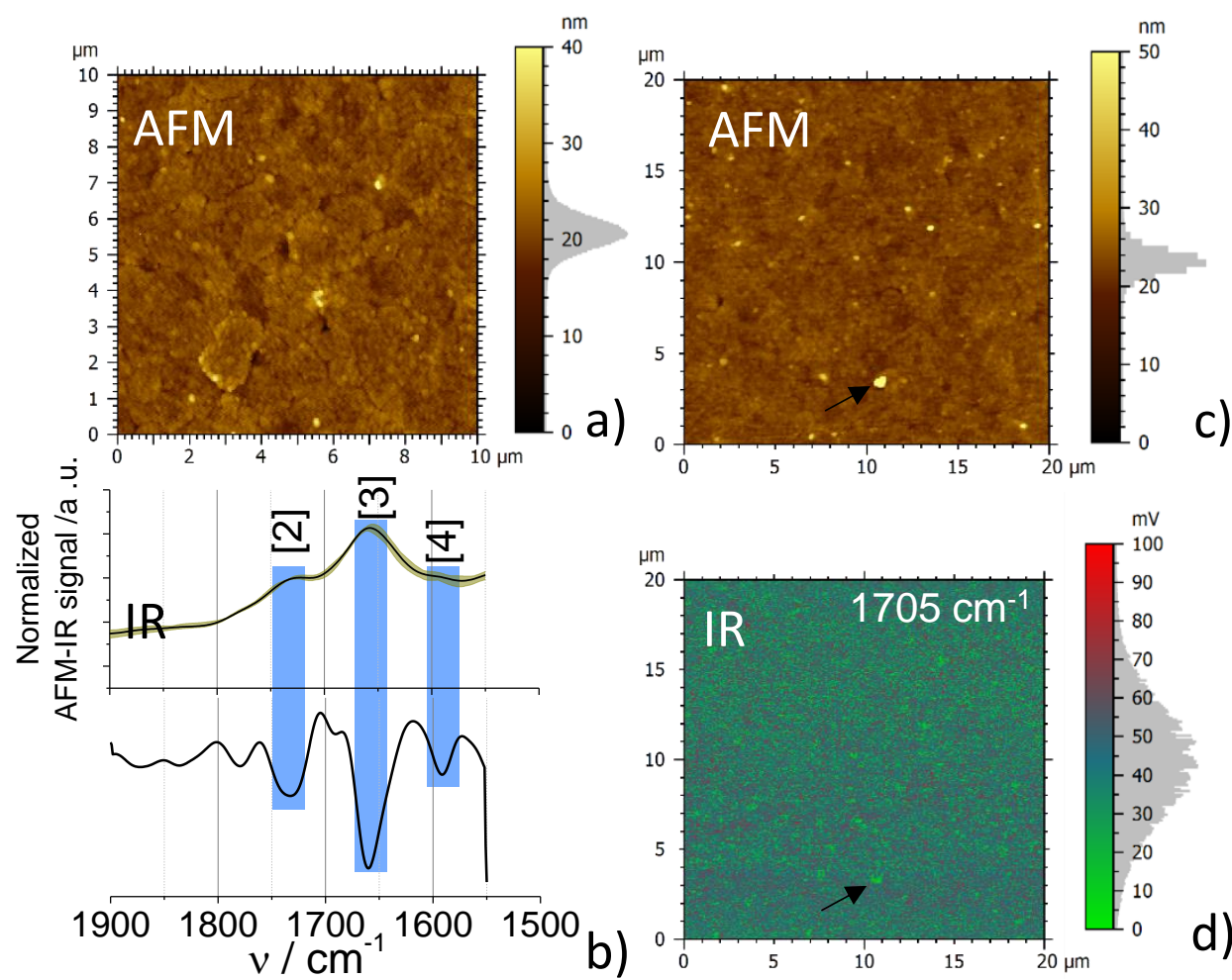

[1]: $1720-1740 \mathrm{~cm}^{-1}-\mathrm{v}(\mathrm{COOH})$ [isolated]

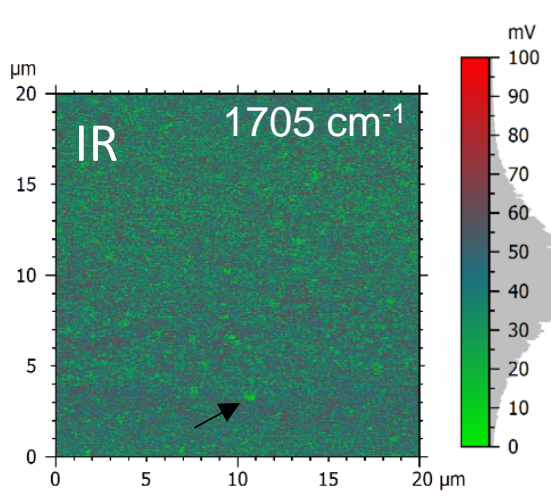

d)

[2]: $1700-1720 \mathrm{~cm}^{-1}-\mathrm{v}(\mathrm{COOH})[\mathrm{H}-$ bonding]

[3]: $1650-1660 \mathrm{~cm}^{-1}-\mathrm{v}\left(\mathrm{H}_{2} \mathrm{O}\right)$ [adsorbed]

[4]: $1580 \mathrm{~cm}^{-1}-\mathrm{v}_{\text {as }}\left(\mathrm{COO}^{-}\right)$

Figure 5 - AFMIR experiments performed on G-C18:0 lipid-coated gold substrates (Sample $\mathbf{N}^{\circ} 175$, Table S 3.) dipped at the optimal conditions of $S_{w}=0.1 \mathrm{~mm} / \mathrm{s}$. a) $10 \times 10 \mu \mathrm{m}$ AFM image and corresponding b) normalized IR absorption spectrum with second derivative given underneath. The background signal (Figure S 5d, average over 15 spectra), measured on a lipid-free gold substrate (Figure S 5b,c), is subtracted from the IR spectrum, which results from the average of 40 spectra, randomly collected on the AFM image in a). The shaded region surrounding the spectrum corresponds to the intensity dispersion evaluated form 
the multiple spectra. Selected spectra (sample and gold reference) prior to normalization are shown in Figure S 7. c) $20 \times 20 \mu \mathrm{m}$ AFM image and corresponding d) $2 D$ IR map recorded at $\nu=1705 \mathrm{~cm}^{-1}$.

Figure 5 and Figure 6 present a series of AFMIR experiments performed at different scales, from $50 \mu \mathrm{m}$ x $50 \mu \mathrm{m}$ to $10 \mu \mathrm{m}$ x $10 \mu \mathrm{m}$, on several G-C18:0 coated gold substrates. All AFM images in Figure 5 and Figure 6, in agreement with the AFM experiments performed on Si wafers (Figure 4), show a homogeneous surface coverage, irrespective of the sample under study and of the region of the substrate, without any irregularity or defect in the coating. The faceted surface texture observed for all samples is not related to the lipid coating but it is typical of these substrates, as shown on AFM image of the lipid-free, control, Au substrate (Figure S $5 b, c)$.

The normalized IR spectra (non-normalized spectra are shown in Figure S 7) and related second derivatives are shown below each AFM image for a given sample in Figure 5 and Figure 6. Due to spectral range of the IR laser source limited to $1945-1510 \mathrm{~cm}^{-1}$, AFMIR covers the $1900<v / \mathrm{cm}^{-1}<1500$ region, which corresponds to the $v(\mathrm{C}=\mathrm{O})$ in $\mathrm{COOH}$ and $v_{\mathrm{s}, \mathrm{as}}(\mathrm{C}=\mathrm{O})$ in $\mathrm{COO}^{-75}$ that is the carboxylic/carboxylate region, typical of G-C18:0 and microbial glycolipids ${ }^{76}$ and excluded in surface organic impurities, generally characterized by the $v_{\mathrm{s} \text {,as }} \mathrm{CH}$ signal above $2000 \mathrm{~cm}^{-1}$. The $\mathrm{COOH}$ group has a typical signature between $1760 \mathrm{~cm}^{-1}$ and 1700 $\mathrm{cm}^{-1}$, depending on the strength of hydrogen bonding, ${ }^{75}$ while $\mathrm{COO}^{-}$has two typical signatures, reported for organic acids at $v_{\text {as }}\left(\mathrm{COO}^{-}\right)=1579 \pm 26 \mathrm{~cm}^{-1}$ and $v_{\mathrm{s}}\left(\mathrm{COO}^{-}\right)=1406 \pm 12 \mathrm{~cm}^{-1},{ }^{75}$ the latter being out of the spectral window in this work. In this regard, AFMIR confirms that the uncoated gold substrate control does not show any spurious signal below $2000 \mathrm{~cm}^{-1}$ (Figure $\mathrm{S}$ $5 \mathrm{~d})$, that is in the range of the $\mathrm{C}=\mathrm{O}$ stretch.

IR data associated to AFM are presented in two formats: typical $I(v)$ spectra and related second derivative (Figure 5b), which correspond to the average of randomly recorded spectra across the surface of the corresponding AFM image (Figure 5a); a 2D IR map, matching the AFM image and with the intensity being associated to the magnitude of the IR signal recorded at $v=1705 \mathrm{~cm}^{-1}$ (Figure 5d).

The $I(v)$ spectra in Figure $5 \mathrm{~b}$ shows three broad maxima, around $1720 \mathrm{~cm}^{-1}$ (peak [2]), $1660 \mathrm{~cm}^{-1}$ (peak [3]) and $1590 \mathrm{~cm}^{-1}$ (peak [4]), well identified by the negative peaks in the underlying second derivative profile. The average value of $v(\mathrm{C}=\mathrm{OOH})$ was reported to be 1723 $\pm 12 \mathrm{~cm}^{-1}$ in a number of aqueous carboxylic acids: high wavenumbers are characteristic of isolated $\mathrm{COOH}$ monomers while lower wavenumbers are found in hydrogen bonded $\mathrm{COOH},{ }^{75}$ including dimers, as shown for stearic acid Langmuir-Blodgett films. ${ }^{77}$ If the broad band around 
$1720 \mathrm{~cm}^{-1}$ confirms the presence of a consolidated carboxylic acid network, consequently demonstrating the presence of G-C18:0, its high wavenumber suggests the coexistence of both isolated $\left(1740 \mathrm{~cm}^{-1}\right)$ and hydrogen-bonded $\left(1700 \mathrm{~cm}^{-1}\right) \mathrm{COOH}$ groups. ${ }^{75}$ The homogeneity of the G-C18:0 coating on the $\mu m$-scale is demonstrated by the 2D cartography in Figure $5 \mathrm{~d}$, recorded at $v=1705 \mathrm{~cm}^{-1}$, thus showing a full $\mathrm{COOH}$ coverage of the gold substrates. Noteworthy, the IR map contains localized green spots (e.g., arrow in Figure 5d), sign of a low IR signal that corresponds to surface impurities easily observable on the corresponding AFM image (e.g., arrow on Figure 5c). Finally, the bands around $1660 \mathrm{~cm}^{-1}$ and $1590 \mathrm{~cm}^{-1}$ are of more straightforward interpretation. The former is attributed to the deformation of adsorbed water (mean value in Ref. ${ }^{75}: 1643 \pm 9 \mathrm{~cm}^{-1}$ ) while the latter to the asymmetrical stretching of the carboxylate group.
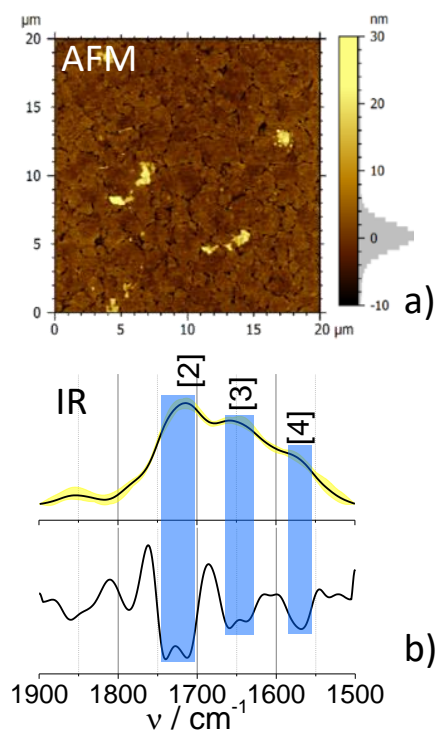

[1]: $1720-1740 \mathrm{~cm}^{-1}-v(\mathrm{COOH})$ [isolated]

[2]: $1700-1720 \mathrm{~cm}^{-1}-\mathrm{v}(\mathrm{COOH})$ [H-bonding]
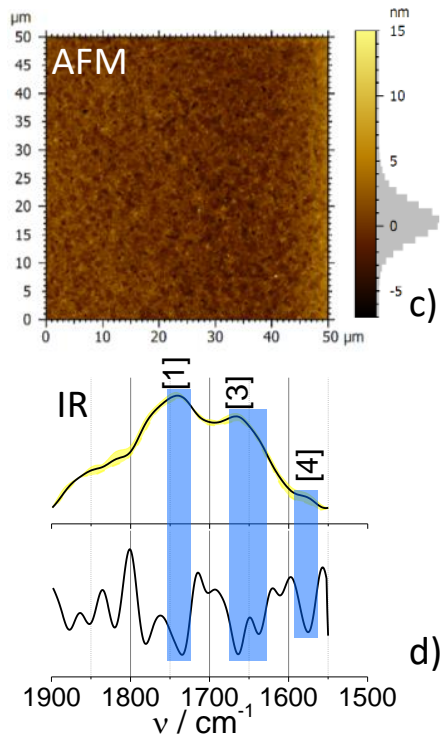

[3]: $1650-1660 \mathrm{~cm}^{-1}-\mathrm{v}\left(\mathrm{H}_{2} \mathrm{O}\right)$ [adsorbed]

[4]: $1580 \mathrm{~cm}^{-1}-\mathrm{v}_{\text {as }}\left(\mathrm{COO}^{-}\right)$
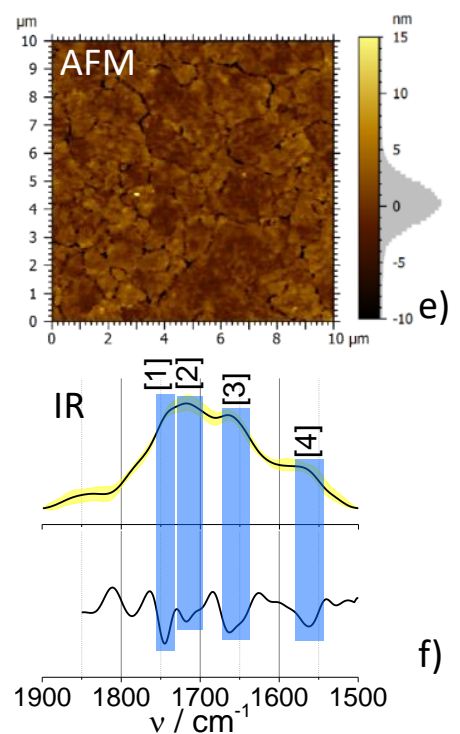

Figure 6-AFMIR experiments performed on G-C18:0 lipid coated gold substrates. Samples are dip-coated at the optimal conditions of $S_{w}=0.1 \mathrm{~mm} / \mathrm{s}$. AFM image (top) and corresponding normalized averaged IR spectra with second derivative (bottom) of samples a,b) $\mathbf{N}^{\circ} 166$ (100 spectra), c,d) $\mathrm{N}^{\circ} 174$ (15 spectra) and e,f) $\mathrm{N}^{\circ} 172$ (75 spectra). Sample list is given in Table S 3. The background signal (Figure S 5d, average over 15 spectra), measured on a lipid-free gold substrate (Figure $S \mathbf{5 b}, \mathrm{c}$ ), is subtracted from the IR spectrum. IR signals are averages of b) 100 , d) 15 and f) 75 spectra randomly collected on their corresponding AFM images. The shaded region surrounding the spectrum corresponds to the dispersion in intensity recorded from multiple spectra.

Figure 6 shows a series of additional AFMIR experiments performed on three additional samples, prepared from both at acidic and basic $\mathrm{pH}$ solutions. Besides the faceted structure, intrinsic to the gold substrates, the AFM images are highly homogeneous for all samples on 
surfaces going from $100 \mu \mathrm{m}^{2}$ to $2500 \mu \mathrm{m}^{2}$. The corresponding IR signals systematically contain the $\mathrm{COOH}$ and $\mathrm{COO}^{-}$signatures, respectively above $1700 \mathrm{~cm}^{-1}$ (peaks [1] and [2]) and around $1590 \mathrm{~cm}^{-1}$ (peak [4]). It is not uncommon to find two well-defined signatures either between 1700 and $1720 \mathrm{~cm}^{-1}$ (peak [2], Figure 6b) and 1720 and $1740 \mathrm{~cm}^{-1}$ (peak [1], Figure 6d) or even coexisting together (peaks [1] and [2], Figure 6f). The relative intensities of peaks [1] and [2] are probably related to a different extent of hydrogen bonding network around the carboxylic acid. However, quantification is a difficult task due to the multicomposite nature of each peak, as shown by the corresponding second derivatives, indicating the presence of both components in the entire $1700-1740 \mathrm{~cm}^{-1}$ region. Nonetheless, AFMIR can be exploited to draw a qualitative description of the local arrangement of the glucolipids.

G-C18:0 forms interdigitated monolayers, where, to the best of our knowledge, $\mathrm{COOH}$ groups are homogeneously distributed on both sides of the membrane (Figure 1). The IR component at $1740 \mathrm{~cm}^{-1}$ (isolated $\mathrm{COOH}$ ) could then be attributed to those G-C18:0 molecules, of which the $\mathrm{COOH}$ directly interacts with gold, while the component at $1720 \mathrm{~cm}^{-1}(\mathrm{COOH}$ engaged in $\mathrm{H}$-bonding) could be attributed to those molecules, of which the $\mathrm{COOH}$ group points outward, interacting with external moisture or adjacent glucose moieties. All second derivatives show the lack of a well-defined peak around $1700 \mathrm{~cm}^{-1}$ for all samples, thus suggesting that the presence of $\mathrm{COOH}$ dimers, as commonly found in multilayers composed of stearic acid, ${ }^{77}$ is limited, if not excluded. Since $\mathrm{COOH}$ dimers could potentially form between superposed lipid layers, this piece of information, in agreement with ellipsometry, also excludes the presence of multilayers and strengthen the formation of SLM.

AFMIR experiments confirm the presence of a homogeneous G-C18:0 membrane at the $\mathrm{nm}$ - and $\mu \mathrm{m}$-scale, supporting the homogeneity found by fluorescence microscopy and ellipsometry at higher scales. However, the high homogeneity and lack of defects in most of the AFM images do not allow to confirm the average thickness measured by ellipsometry. The only AFMIR experiment in our possession and which demonstrates the presence of a mostly single G-C18:0 layer, could be performed on a poorly-homogeneous, peripheral, region of a coated Si wafer, shown in Figure S 8 and discussed on Page S19.

AFMIR experiments show that all selected samples contain signals of the $\mathrm{COOH}$ and $\mathrm{COO}^{-}$groups as well as adsorbed water across the entire surface, which is generally homogeneously covered from the $\mathrm{nm}$ - to the $\mu \mathrm{m}$-scale. These signals, systematically coexisting in aqueous environments of carboxylic acids, ${ }^{75}$ provide the unambiguous proof that the GC18:0 homogeneously covers the entire surface. G-C18:0 coatings are so homogeneous that practically all AFM experiments performed in this work, on both Si wafer and Au substrate, 
cannot provide a reliable estimation of their thickness, when classical AFM images performed on SLB display local defects, holes or multilayer adsorption, ${ }^{23,46,48,51,78}$ in the absence of which AFM is in fact unable to measure the thickness. ${ }^{27}$ Even surface scratching, representing a possible method to peel off part of the coating and measure its thickness with respect to the accessible substrate, is not advised in the case of SLB. It was shown that lipids can be lied down on the surface, instead of being peeled off, they can adsorb onto the tip or they can also diffuse back to fill up the hole soon after scratching. ${ }^{64-67}$ Nonetheless, in the lone experiment showing a peripheral region rich in defects, AFMIR shows the presence of mostly single lipid layers, in agreement with the thickness estimations by ellipsometry for those samples displaying $2<T_{h} /$ $\mathrm{nm}<5$ (Figure 2b,d).

Defect-free SLB is a long-date issue ${ }^{23,24}$ and such a good, defect-free, homogeneity from the $\mathrm{cm}$ to the $\mathrm{nm}$ scales is relatively rare to obtain, all methods taken together. ${ }^{24,41,45,51}$ From the Langmuir-Blodgett and vesicle fusion methods, the most common ones in SLB synthesis, it is known that deposition of the lipid gel phase, below the melting temperature, $T_{\mathrm{m}}$, provides a good SLB homogeneity. ${ }^{24,41}$ However, preparing an SLB in the lipid gel phase using the vesicle fusion method decreases the chance to fuse vesicle together, but it increases the risk to find unexplosed vesicles on the SLB. ${ }^{41}$ The general approach in the vesicle fusion method is then to prepare SLB in the bilayer fluid phase, above the $T_{\mathrm{m}}$, and then decrease the temperature. However, this process generally provides highly defectuous SLB due to intra-bilayer tensions and cracking. ${ }^{23,24,47,64}$ The situation is opposite when preparing SLB from the LB approach. If nearly defect-free SLB could be prepared by LB below the lipid $T_{\mathrm{m}}$, approaching the gel-tofluid transition by increasing the temperature induces defects in the SLB. ${ }^{24}$ What then determines the best approach is the value of the $T_{\mathrm{m}}$, that is the type of lipid or lipid formulation. For instance, to prepare a homogeneous SLB at room temperature it could be interesting to employ the LB method in combination with DPPC (L- $\alpha$-dipalmitoylphosphatidylcholine), which has a $T_{\mathrm{m}}$ of $41^{\circ} \mathrm{C}$, while vesicle fusion could be more adapted for DOPC (L- $\alpha-$ dioleoylphosphatidylcholine;), of which the $T_{\mathrm{m}}$ is below $0^{\circ} \mathrm{C} .^{23,24}$

In this work, we have worked with a glycolipid of which the $T_{\mathrm{m}}$ is close to $37^{\circ} \mathrm{C},{ }^{56}$ meaning that dip-coating below about $40^{\circ} \mathrm{C}$, and in particular at room temperature, constitute the best conditions to obtain highly homogeneous, defect-free, coatings, a fact which is experimentally verified for most samples studied here at $S_{w}=0.13 \pm 0.10 \mathrm{~mm} / \mathrm{s}$. Our previous work on the surface self-assembly of sophorolipids did show that the surface energy strongly influences the surface patterns. Inhomogeneous patches and fibrillary aggregates were then found. In the present work, the hypothesis formulated in Figure 1b, according to which the G- 
C18:0 interdigitated flat membranes are transferred as such from the solution onto the substrate is actually plausible. This mechanism recalls a coating mechanism similar to what it is described for LB coatings below the lipid $T_{\mathrm{m}}$, the main difference being that the G-C18:0 membrane is obtained by pre-formed, colloidally-stable, lamellae in solution and not from molecular layers at the liquid-air interface. This assumption is supported by the fact that the optimal concentration to obtain homogeneous supported G-C18:0 layers with thickness between 2 and $5 \mathrm{~nm}$ is set at $5 \mathrm{mg} / \mathrm{mL}$, when the colloidal G-C18:0 interdigiated monolayers are fully formed. ${ }^{20,21}$ On the contrary, more diluted solutions $(1$ and $3 \mathrm{mg} / \mathrm{mL}$ ) provide coatings with thickness below $2 \mathrm{~nm}$, indicative of highly defectuous, or inhomogeneous, coatings. Finally, using a colloidal lamellar soliution instead of vesicles is a clear advantage, because the risk of depositing unexplosed vesicles, classical in the vesicle fusion method, ${ }^{38}$ is reduced.

When comparing the spin- and dip-coating methods, we find a good homogeneity and the possibility to form single lipid layers. Compared to spin-coating, where the only control parameter is the lipid concentration in solution, ${ }^{38}$ dip-coating offers a multitude of parameters (concentration, temperature, withdrawal rate, relative humidity) to control the thickness and homogeneity of the coating. In addition, high lateral pressure during sample spinning were depicted as major causes of SLB inhomogeneity in the spin-coating approach. ${ }^{48}$ Dip-coating is a more gentle technique, where anisotropic pressure is not present during coating, thus eliminating additional sources of interdigitation, phase transition or hole formation. Finally, differently than both spin- and horizontal coating evaporation-induced method, ${ }^{51}$ dip-coating is easily upscalable and it can be used to coat substrates of virtually any size and morphology, thus being potentially interesting for a broader number of applications. ${ }^{79}$

\section{Conclusion}

Glycosylated supported lipid monolayers are prepared by dispersing an aqueous solution of a diluted, colloidally-stable, lamellar phase of a glucolipid obtained by microbial fermentation. A silicon wafer or gold substrate are dipped into a solution containing a dispersed lamellar phase only composed of the glucolipid. Highly homogeneous, crack-free, lipid layers of thickness, $T_{h}=2.8 \pm 1.0 \mathrm{~nm}$ are formed at a withdrawal rate of $S_{w}=0.13 \pm 0.10 \mathrm{~mm} / \mathrm{s}$. The error on the thickness is obtained by averaging not less than 26 experiments, each performed from acidic or basic $\mathrm{pH}$ glucolipid solutions within a broad range of temperature $\left(T=30 \pm 10^{\circ} \mathrm{C}\right)$ and relative humidity $(R H \%=55 \pm 10 \%)$ conditions, demonstrating the robustness of the present approach. 
The quality of the fits associated to the amplitude, $\Psi(\lambda)$, and phase difference, $\Delta(\lambda)$, spectra in ellipsometry experiments is very good for the samples prepared at $S_{w}=0.13 \pm 0.10$ $\mathrm{mm} / \mathrm{s}$. This supports a high homogeneity of the coatings on the $\mathrm{cm}$-scale. Fluorescence microscopy systematically shows a highly homogeneous, poorly contrasted, signal, supporting the homogeneity at the $m m$-scale level. Standard AFM and AFM coupled to infrared spectroscopy (AFMIR) performed on samples prepared at $S_{w}=0.13 \pm 0.10 \mathrm{~mm} / \mathrm{s}$ show an impressive homogeneity at the $\mu m$ - and $\mathrm{nm}$-scale. In general, no distinctive sign of crack, hole or multiple layer is observed. Both randomly-collected single-point and $2 \mathrm{D}$ cartographic IR spectra show that the signal of the $\mathrm{COOH}\left(v(\mathrm{C}=\mathrm{O})\right.$ at $\left.1700-1740 \mathrm{~cm}^{-1}\right)$ and $\mathrm{COO}^{-}\left(v_{\mathrm{s}, \mathrm{as}}(\mathrm{C}=\mathrm{O})\right.$ at $1590 \mathrm{~cm}^{-1}$ ) groups of the glucolipid are homogeneously distributed across the entire surface for any of the analyzed surfaces.

In summary, the combined use of the dip-coating process with a preformed aqueous glucolipid lamellar phase de facto constitutes an ideal approach to prepare defect-free, highly homogeneous, supported lipid layers across the $\mathrm{nm}$ - to $\mathrm{cm}$-scale under practical environmental conditions.

\section{Acknowledgements}

Dr. S. Roelants (InBio.be, Gent University, Belgium) and Prof. Chris V. Stevens (SynBioC, Gent University, Belgium) are kindly acknowledged for providing the G-C18:0 lipid.

\section{References}

1 A. Bernardi, J. Jiménez-Barbero, A. Casnati, C. De Castro, T. Darbre, F. Fieschi, J. Finne, H. Funken, K.-E. Jaeger, M. Lahmann, T. K. Lindhorst, M. Marradi, P. Messner, A. Molinaro, P. V. Murphy, C. Nativi, S. Oscarson, S. Penadés, F. Peri, R. J. Pieters, O. Renaudet, J.-L. Reymond, B. Richichi, J. Rojo, F. Sansone, C. Schäffer, W. B. Turnbull, T. Velasco-Torrijos, S. Vidal, S. Vincent, T. Wennekes, H. Zuilhof and A. Imberty, Chem. Soc. Rev., 2013, 42, 4709-4727.

2 S. M. Brosnan, H. Schlaad and M. Antonietti, Angew. Chemie - Int. Ed., 2015, 54, 9715-9718.

3 J. Rojo, V. Díaz, J. M. De La Fuente, I. Segura, A. G. Barrientos, H. H. Riese, A. Bernad and S. Penadés, ChemBioChem, 2004, 5, 291-297.

4 T. Weber, V. Chrasekaran, I. Stamer, M. B. Thygesen, A. Terfort and T. K. Lindhorst, Angew. Chemie - Int. Ed., 2014, 53, 14583-14586.

5 P. M. Claesson, in Biopolymers at Interfaces, Second Edition, ed. M. Malmsten, CRC Press, Surfactant., 2003, p. 165.

6 N. Hao, K. Neranon, O. Ramström and M. Yan, Biosens. Bioelectron., 2016, 76, 113-130. 
O. Ramström and M. Yan, Chem. - A Eur. J., 2015, 21, 16310-16317.

8 X. Chen, O. Ramström and M. Yan, Nano Res., 2014, 7, 1381-1403.

9 B. Kav, A. Grafmueller, E. Schneck and T. R. Weikl, Nanoscale, 2020, 17342-17353.

T. Fyrner, H. H. Lee, A. Mangone, T. Ekblad, M. E. Pettitt, M. E. Callow, J. A. Callow, S. L. Conlan, R. Mutton, A. S. Clare, P. Konradsson, B. Liedberg and T. Ederth, Langmuir, 2011, 27, 15034-15047.

C. Valotteau, C. Calers, S. Casale, J. Berton, C. V. Stevens, F. Babonneau, C. M. Pradier, V. Humblot and N. Baccile, ACS Appl. Mater. Interfaces, 2015, 7, 18086-18095.

C. Valotteau, I. M. Banat, C. A. Mitchell, H. Lydon, R. Marchant, F. Babonneau, C.-M. M. Pradier, N. Baccile and V. Humblot, Colloids Surfaces B Biointerfaces, 2017, 157, 325-334.

D. Di Iorio, M. L. Verheijden, E. Van Der Vries, P. Jonkheijm and J. Huskens, ACS Nano, 2019, 13, 3413-3423.

R. Marchant and I. M. Banat, Trends Biotechnol., 2012, 30, 558-565.

J. D. Desai and I. M. Banat, Microbiol. Mol. Biol. Rev., 1997, 61, 47-64.

C. Valotteau, N. Baccile, V. Humblot, S. Roelants, W. Soetaert, C. V. Stevens and Y. F. Dufrêne, Nanoscale Horizons, 2019, 4, 975-982.

17 M. L. Chen, J. Penfold, R. K. Thomas, T. J. P. P. Smyth, A. Perfumo, R. Marchant, I. M. Banat, P. Stevenson, A. Parry, I. Tucker, I. Grillo, C. ML, M. L. Chen, J. Penfold, R. K. Thomas, T. J. P. P. Smyth, A. Perfumo, R. Marchant, I. M. Banat, P. Stevenson, A. Parry, I. Tucker and I. Grillo, Langmuir, 2010, 26, 18281-18292.

M. Chen, C. Dong, J. Penfold, R. K. Thomas, T. J. P. Smyth, A. Perfumo, R. Marchant, I. M. Banat, P. Stevenson, A. Parry, I. Tucker and I. Grillo, Langmuir, 2013, 29, 3912-3923.

N. Baccile, F. Babonneau, J. Jestin, G. Pehau-Arnaudet, I. Van Bogaert, G. Péhau-Arnaudet, I. Van Bogaert, G. Pehau-Arnaudet and I. Van Bogaert, ACS Nano, 2012, 6, 4763-4776.

N. Baccile, M. Selmane, P. Le Griel, S. Prévost, J. Perez, C. V. Stevens, E. Delbeke, S. Zibek, M. Guenther, W. Soetaert, I. N. A. Van Bogaert and S. Roelants, Langmuir, 2016, 32, 63436359.

21 N. Baccile, A.-S. Cuvier, S. Prévost, C. V Stevens, E. Delbeke, J. Berton, W. Soetaert, I. N. A. Van Bogaert and S. Roelants, Langmuir, 2016, 32, 10881-10894.

Y. Ishigami, Y. Gama, H. Nagahora, M. Yamaguchi, H. Nakahara and T. Kamata, Chem. Lett., 1987, 16, 763-766.

L. K. Tamm and H. M. McConnell, Biophys. J., 1985, 47, 105-113.

24 J. Kurniawan, J. F. Ventrici de Souza, A. T. Dang, G. Liu and T. L. Kuhl, Langmuir, 2018, 34, $15622-15639$.

25 G. J. Hardy, R. Nayak and S. Zauscher, Curr. Opin. Colloid Interface Sci., 2013, 18, 448-458.

26 E. T. Castellana and P. S. Cremer, Surf. Sci. Rep., 2006, 61, 429-444.

27 S. Morandat and K. El Kirat, Colloids Surfaces B Biointerfaces, 2007, 55, 179-184. 
P. Wessman, A. A. Strömstedt, M. Malmsten and K. Edwards, Biophys. J., 2008, 95, 4324 4336.

Y. K. Lee, H. Lee and J. M. Nam, NPG Asia Mater., 2013, 5, 1-13.

30 F. Wang, J. H. Seo, G. Luo, M. B. Starr, Z. Li, D. Geng, X. Yin, S. Wang, D. G. Fraser, D. Morgan, Z. Ma and X. Wang, Nat. Commun., 2016, 7, 10444.

31 T. Fujie, S. Ahadian, H. Liu, H. Chang, S. Ostrovidov, H. Wu, H. Bae, K. Nakajima, H. Kaji and A. Khademhosseini, Nano Lett., 2013, 13, 3185.

32 B. Yuan, Y. Li, D. Wang, Y. Xie, Y. Liu, L. Cui, F. Tu, H. Li, H. Ji, W. Zhang and X. Jiang, Adv. Funct. Mater., 2010, 20, 3715.

33 E. Kang, J. Ryoo, G. S. Jeong, Y. Y. Choi, S. M. Jeong, J. Ju, S. Chung, S. Takayama and S. H. Lee, Adv. Mater., 2013, 25, 2167.

34 M. Wlodek, M. Kolasinska-Sojka, M. Szuwarzynski, S. Kereïche, L. Kovacik, L. Zhou, L. Islas, P. Warszynski and W. H. Briscoe, Nanoscale, 2018, 10, 17965-17974.

J. Fleddermann, E. Diamanti, S. Azinas, M. Košutić, L. Dähne, I. Estrela-Lopis, M. Amacker, E. Donath and S. E. Moya, Nanoscale, 2016, 8, 7933-7941.

36 H. A. Rinia, R. A. Demel, J. P. van der Eerden and B. de Kruijff, Biophys. J., 1999, 77, 168393.

E. Kalb, S. Frey and L. K. Tamm, Biochim. Biophys. Acta, 1992, 1103, 307-316.

G. Csùcs and J. J. Ramsdem, Biochim. Biophys. Acta, 1998, 1369, 61-70.

M. C. Howland, A. W. Szmodis, B. Sanii and A. N. Parikh, Biophys. J., 2007, 92, 1306-17.

40 S. J. Johnson, T. M. Bayerl, D. C. McDermott, G. W. Adam, A. R. Rennie, R. K. Thomas and E. Sackmann, Biophys. J., 1991, 59, 289-294.

41 T. K. Lind and M. Cárdenas, Biointerphases, 2016, 11, 020801.

42 B. Sironi, T. Snow, C. Redeker, A. Slastanova, O. Bikondoa, T. Arnold, J. Kleine and W. H. Briscoe, Soft Matter, 2016, 12, 3877-3887.

43 I. Möller and S. Seeger, J. Mater. Chem. B, 2015, 3, 6046-6056.

44 R. Caminiti, G. Caracciolo, M. Pisani and P. Bruni, Chem. Phys. Lett., 2005, 409, 331-336.

45 U. Mennicke and T. Salditt, Langmuir, 2002, 18, 8172-8177.

46 L. Krapf, M. Dezi, W. Reichstein, J. Köhler and S. Oellerich, Colloids Surfaces B Biointerfaces, 2011, 82, 25-32.

47 A. C. Simonsen and L. A. Bagatolli, Langmuir, 2004, 20, 9720-9728.

48 A. Dols-Perez, L. Fumagalli and G. Gomila, Colloids Surfaces B Biointerfaces, 2018, 172, 400-406.

49 J. Generosi, C. Castellano, D. Pozzi, A. Congiu Castellano, R. Felici, F. Natali and G. Fragneto, J. Appl. Phys., 2004, 96, 6839-6844.

50 L. Perino-Gallice, G. Fragneto, U. Mennicke, T. Salditt and F. Rieutord, Eur. Phys. J. E, 2002, 8, 275-282. 
M. Le Berre, Y. Chen and D. Baigl, Langmuir, 2009, 25, 2554-2557.

52 N. Baccile, C. Seyrig, A. Poirier, S. A. Castro, S. L. K. W. Roelants and S. Abel, Green Chem., 2021, 23, 3842-3944.

53 J. Peyre, A. Hamraoui, M. Faustini, V. Humblot and N. Baccile, Phys. Chem. Chem. Phys., 2017, 19, 15227-15238.

54 M. Faustini, M. Faustini, B. Louis, P. A. Albouy, M. Kuemmel and D. Grosso, J. Phys. Chem. $C, 2010,114,7637-7645$.

55 K. M. J. Saerens, J. Zhang, L. Saey, I. N. A. Van Bogaert and W. Soetaert, Yeast, 2011, 28, 279-292.

56 G. Ben Messaoud, P. Le Griel, S. Prévost, D. H. Merino, W. Soetaert, S. L. K. W. Roelants, C. V. Stevens and N. Baccile, Soft Matter, 2020, 16, 2528-2539.

57 G. Ben Messaoud, P. Le Griel, D. H. Merino and N. Baccile, Soft Matter, 2020, 16, 25402551.

R. Nagarajan, Chem. Eng. Commun., 1987, 55, 251-273.

59 N. Baccile and V. Cristiglio, Langmuir, 2020, 36, 2191-2198.

60 K. Kolahdouzan, J. A. Jackman, B. K. Yoon, M. C. Kim, M. S. Johal and N. J. Cho, Langmuir, 2017, 33, 5052-5064.

61 S. M. Baumler, A. M. McHale and G. J. Blanchard, J. Electroanal. Chem., 2018, 812, 159 165.

62 F. Gołek, P. Mazur, Z. Ryszka and S. Zuber, Appl. Surf. Sci., 2014, 304, 11-19.

63 J. M. Solletti, J. Vac. Sci. Technol. B Microelectron. Nanom. Struct., 1996, 14, 1492.

64 A. Charrier and F. Thibaudau, Biophys. J., 2005, 89, 1094-1101.

65 M. F. Luo, Y. L. Yeh, P. L. Chen, C. H. Nien and Y. W. Hsueh, J. Chem. Phys., , DOI:10.1063/1.2194539.

66 S. Garcia-Manyes, O. Domènech, F. Sanz, M. T. Montero and J. Hernandez-Borrell, Biochim. Biophys. Acta, 2007, 1768, 1190-8.

67 N. C. Santos, E. Ter-Ovanesyan, J. A. Zasadzinski and M. A. R. B. Castanho, Biophys. J., 1998, 75, 2119-2120.

68 A. Dazzi, R. Prazeres, F. Glotin and J. M. Ortega, Opt. Lett., 2005, 30, 2388.

69 F. Lu, M. Jin and M. A. Belkin, Nat. Photonics, 2014, 8, 307-312.

70 F. Lu and M. A. Belkin, Opt. Express, 2011, 19, 19942.

71 A. Dazzi, R. Prazeres, F. Glotin, J. M. Ortega, M. Al-Sawaftah and M. de Frutos, Ultramicroscopy, 2008, 108, 635-641.

72 T. Awatani, H. Midorikawa, N. Kojima, J. Ye and C. Marcott, Electrochem. commun., 2013, 30, 5-8.

73 J. R. Felts, S. Law, C. M. Roberts, V. Podolskiy, D. M. Wasserman and W. P. King, Appl. Phys. Lett., 2013, 102, 152110. 
74 A. Deniset-Besseau, C. B. Prater, M. J. Virolle and A. Dazzi, J. Phys. Chem. Lett., 2014, 5, 654-658.

75 J. J. Max and C. Chapados, J. Phys. Chem. A, 2004, 108, 3324-3337.

76 N. Baccile, R. Noiville, L. Stievano and I. Van Bogaert, Phys. Chem. Chem. Phys., 2013, 15, $1606-1620$.

77 F. Kimura, J. Umemura and T. Takenaka, Langmuir, 1986, 2, 96-101.

78 S. Morandat, S. Azouzi, E. Beauvais, A. Mastouri and K. El Kirat, Anal. Bioanal. Chem., 2013, 405, 1445-1461.

79 J. Puetz and M. A. Aegerter, in Sol-Gel Technologies for Glass Producers and Users, Springer, Boston, MA, 2004, pp. 37-48. 


\section{Legend of Figures in the Supporting Information}

Figure S 1 - Scheme and images of the dip-coating system and apparatus

Figure $S 2$ - a) Scheme of multilayer model employed to fit the fit $\Psi(\lambda)$ and $\Delta(\lambda)$ spectra obtained by ellipsometry on samples coated on commercial silicon wafers. The typical fitted $\Psi(\lambda)$ and $\Delta(\lambda)$ spectra for selected samples are given for samples (Table $S 3$ ): b) commercial Si wafer control, c) $N^{\circ} 203$, d) $N^{\circ} 176$, e)

$\mathrm{N}^{\circ}$ 167. Typical good (d-e) and poor (c) quality fits are given on purpose.

Table S 1 - Fitted values of the thickness, $T_{h}$, and fit quality for Si wafer control and samples shown Figure $S$ 2. $T_{h}$ is the average of the thickness values obtained with refractive index of 1.4 an 1.7 (lower and upper maximum reported for homogeneous, dense, lipid bilayers).

Figure S 3 - a) Scheme of multilayer model employed to fit the fit $\Psi(\lambda)$ and $\Delta(\lambda)$ spectra obtained by ellipsometry on samples coated on commercial Au substrates. The typical fitted $\Psi(\lambda)$ and $\Delta(\lambda)$ spectra for selected samples are given for samples (Table S 3): b) commercial Au substrate control, c) $\mathbf{N}^{\circ} 158$.

Table S 2 - Fitted values of the thickness, $T_{h}$, and fit quality for Au substrate control and sample shown Figure $S$ 2. $T_{h}$ is the average of the thickness values obtained with refractive index of 1.4 an 1.7 (lower and upper maximum reported for homogeneous, dense, lipid bilayers).

Figure $S 4-$ a) Evolution of $T_{h}$ as a function of the G-C18:0 lipid concentration in the parent solution. The specific conditions of $\mathrm{pH}, S_{w}, \mathrm{RH} \%$ and $\mathrm{T}$ are given on the figures. The conditions for each plotted sample are given in Table $S$ 3. Samples $N^{\circ}$ are 99-139, 155-157, 159, 161, 163, 165, 167, 171. b) Evolution of $T_{h}$ as a function of the relative humidity in the dip-coating chamber. The specific conditions of solution concentration, $C, S_{w}$ and $T$ are given on the figures. Red circles and black stars respectively correspond to the $\mathrm{pH}$ of the parent solution. The conditions for each plotted sample are given in Table $\mathrm{S}$ 3. Sample $\mathbf{N}^{\circ}$ associated to red circles are: $155-157,159,161,163,165,167,171$, while sample $\mathrm{N}^{\circ}$ for black stars are: 41 , 42, 50, 54-64, 69, 142-143, 145-154, 174, 176

Table S 3 - Full list of samples prepared in this work. The concentration, $C$, and pH are meant for the parent solution before dip-coating. Temperature, $T$, and relative humidity, $R H \%$, are meant inside the dipcoating chamber, during dip-coating. $S_{w}$ : withdrawal speed, $T_{h}$ : thickness of the lipid film; $\sigma$ : standard deviation; Typical fit of poor and good quality are respectively given, as an example, in

Figure S 2c and Figure S 2d. Green lines: samples at pH 6 plotted in Figure 2 in the main text; Red lines: samples at pH 9 plotted in Figure 2 in the main text.

Table S 4 - Surface roughness calculated from the $h(d)$ profiles (h is the height in $\mathrm{nm}$ and $d$ is the distance in $\mu \mathrm{m}$ ) for samples corresponding to AFM images in Figure 4 (Sample list is given in Table S 3) and to the 
bare control silicon substrate in Figure S 5a. For sample 176 in profile Figure 4a), only the $13<\mathrm{d}(\mu \mathrm{m})<40$ region is considered to avoid the peak and valley artifacts. $\mathbf{R}_{\mathrm{q}}$ : root mean squared roughness; $\mathbf{R}_{\text {sk }}$ : skewness; $R_{v}$ : valley roughness, lowest value of height; $R_{p}$ : peak roughness, highest value of height; $\Delta_{\mathrm{RpRv}}$ : peak-tovalley roughness, largest height amplitude. In the formulas, $n$ is the number of height values in the $h(d)$ profiles.

Figure S 5 - a) AFM image and corresponding height -distance, $h(d)$, profile (white segmeted line) measured on a commercial Si wafer control substrate. b) Large-scale AFM image of the Au control substrate. c) Magnified AFM image of the Au control substrate showing the typical mosaic-like structure composed of Au (111) crystalline domains (white segmented lines). d) IR spectrum measured by AFMIR experiments on the Au substrate. The spectrum is the resul of 15 averaged spectra collected randomly on the corresponding AFM image in b). The gold substrate control displays no IR signal in the IR region between 1900 and 1500 $\mathbf{c m}^{-1}$.

Figure S 6 - a-d) Fluorescence microscopy and e-f) ellipsometry experiments. Sample $N^{\circ} 174\left(\right.$ a) and $N^{\circ} 173$ are respectively prepared on gold and $\mathrm{Si}$ wafer substrates and they are dip-coated from the same parent solution employing the same conditions. Similarly, sample $N^{\circ} 166(c, e)$ and $N^{\circ} 167(d, f)$ are respectively prepared on gold and Si wafer substrates and they are dip-coated from the same parent solution employing the same conditions. Exact conditions for each samples are given in Table $\mathbf{S} 3$.

Table S 5 - Fitted values of the thickness, $T_{h}$, and fit quality for samples $N^{\circ} 166$ and $N^{\circ} 167$, respectively prepared using Au and Si wafer substrates from the same G-C18:0 lipid solution and using the same dipcoating parameters (experimental details are in Table S 3). $T_{h}$ is the average of the thickness values obtained with refractive index of 1.4 an 1.7 (lower and upper maximum reported for homogeneous, dense, lipid bilayers).

Figure S 7 - Non-normalized IR spectra corresponding to the AFMIR experiment performed on G-C18:0 lipid-coated gold substrates (Sample $N^{\circ} 175$, Table $S$ 3) dipped at the optimal conditions of $S_{w}=0.1 \mathrm{~mm} / \mathrm{s}$. Each spectrum is the average of 5 spectra, randomly collected on the AFM image presented in Figure 5a in the main text. The Au control background signal is presented on Figure $S 5 d$ and measured on a lipid-free gold substrate (Figure $S$ 5b,c).

Figure S 8 - Coupled AFMIR experiment performed on sample $\mathrm{N}^{\circ} 58$ (Table S 3) prepared on a Si wafer substrate. a) AFM image and corresponding thickness profile (green line), $h(d)$, measured along the white thick line. b) 2D IR cartography recorded at $1710 \mathrm{~cm}^{-1}$ and corresponding to the AFM image in a). Segmented regions labelled 1,2 and 3 in a) and b) correspond to the Si wafer substrate (1-labelled), singlelayer (2-labelled) and double-layer (3-labelled) G-C18:0 coating. 
3 Homogeneous Supported Monolayer from Microbial Glycolipid 4 Biosurfactant

5

6 Niki Baccile, ${ }^{\mathrm{a}, *}$ Anyssa Derj, ${ }^{\mathrm{a}}$ Cédric Boissière, ${ }^{\mathrm{a}}$ Vincent Humblot, ${ }^{\mathrm{b}, \mathrm{c}}$ Ariane Deniset-Besseau ${ }^{\mathrm{d}}$ 7

8 a Sorbonne Université, Centre National de la Recherche Scientifique, Laboratoire de Chimie de 9 la Matière Condensée de Paris, LCMCP, F-75005 Paris, France

${ }^{\mathrm{b}}$ Sorbonne Université, Laboratoire de Réactivité de Surface (LRS), UMR CNRS 7197, 4 place Jussieu, 11 Paris, F-75005, France

${ }^{c}$ Current address : FEMTO-ST Institute, UMR CNRS 6174, Université Bourgogne FrancheComté, 15B avenue des Montboucons, 25030 Besançon Cedex, France

${ }^{d}$ Université Paris-Saclay, CNRS, Institut de Chimie Physique, UMR 8000, 91405, Orsay, 15 France 


\section{Experimental Section}

Chemicals. The microbial monounstaurated glucolipid G-C18:1 has been produced at a production rate of $\sim 0.5 \mathrm{gL}^{-1} \mathrm{~h}^{-1}$ in a bioreactor system using a modified strain ( $\left.\triangle u g t B 1\right)$ of the yeast Starmerella bombicola and based on the experimental conditions described by Saerens et al. ${ }^{1}$ Thereafter, the fully saturated G-C18:0 $\left(\mathrm{M}_{\mathrm{w}}=462.6 \mathrm{~g} \cdot \mathrm{mol}^{-1}\right)$, employed in this work (Figure $1 \mathrm{a}$ in the main text), is obtained from G-C18:1 by a catalytic hydrogenation reaction described elsewhere. $^{2}$ The full characterization of G-C18:0 is reported in ref. ${ }^{2}$. 1,2-dioleoyl-sn-glycero3-phosphoethanolamine- $\mathrm{N}$-(lissamine rhodamine $\mathrm{B}$ sulfonyl) ammonium salt, (Liss, $\mathrm{M}_{\mathrm{w}}=$ 1301.7 g.mol $\left.{ }^{-1}, \lambda_{\mathrm{abs}}=560 \mathrm{~nm}, \lambda_{\mathrm{em}}=583 \mathrm{~nm}\right)$, is purchased by Avanti ${ }^{\circledR}$ Polar, Inc. Base $(\mathrm{NaOH})$ solutions and acetic acid (Sigma Aldrich) are used with the following molarities: $5 \mathrm{M}, 1 \mathrm{M}, 0.5$ $\mathrm{M}$ and $0.1 \mathrm{M} \mathrm{NaOH}$. All solutions have been prepared with Milli-Q-grade water.

Substrates. Boron-doped one-sided polished $\mathrm{Si}(100)$ wafers (thickness $0.7 \mathrm{~mm}$ ) are cut in approximately $3 \mathrm{~cm} \times 1.5 \mathrm{~cm}$ plates using a diamond pen, then washed using ethanol $96 \%$ and dried using nitrogen gas. Silicon wafers have a typical native $\mathrm{SiO}_{2}$ coating of few $\AA$. $\mathrm{Au}(111)$ substrates $\left(1 \mathrm{~cm}^{2} \times 1 \mathrm{~cm}^{2}\right)$, purchased from Arrandee (Werther, Germany), are composed of a $1 \mathrm{~mm} \mathrm{SiO}_{2}$ glass substrate coated with $50 \AA$ thick chromium and $200 \mathrm{~nm}$ thick Au layers. Gold substrates are annealed using a butane flame to ensure good crystallinity and eventually rinsed with $96 \%$ ethanol under sonication during $5 \mathrm{~min}$.

Solutions. We initially prepare a stock solution ( $V=10 \mathrm{~mL})$ of G-C18:0 at $C=5 \mathrm{mg} / \mathrm{mL}$ and $\mathrm{pH}$ $\sim 9.3$, adjusted using few ( 1-3) $\mu \mathrm{L}$ of a $5 \mathrm{M} \mathrm{NaOH}$ solution. Stock solution is employed to prepare three solutions of $3 \mathrm{~mL}$ each at concentration $C=5 \mathrm{mg} / \mathrm{mL}, 3 \mathrm{mg} / \mathrm{mL}, 1 \mathrm{mg} / \mathrm{mL}$, of which the $\mathrm{pH}$ is lowered to about 6 using few $\mu \mathrm{L}(\sim 5-10)$ of a $0.1 \mathrm{M} \mathrm{HCl}$ solution. These solutions are used as such for dip-coating experiments.

For fluorescence emission experiments, a methanolic solution of Liss $(4 \mathrm{mg} / \mathrm{mL}, 3.08 \mathrm{mM})$ is added to the sample solution prior to dip coating so that the final molar ratio between G-C18:0 and Liss is, G-C18:0:Liss= 200:1. Liss is a standard marker for lipid bilayers for it's lipid backbone is assumed to intercalate in the lipid bilayer without perturbing it, when the lipid:dye molar ratio $\geq 100$. $^{3,4}$

Dip-coating. Dip coating is performed using a ACEdip 2.0 dip-coater (SolGelWay, France), which allows a precise control of the withdrawal rate, $S_{w}$, between $0.001 \mathrm{~mm} / \mathrm{s}$ to $30 \mathrm{~mm} / \mathrm{s}$ and temperature, $T$. Relative humidity, $R H \%$, in the dip-coating chamber is controlled via the Gas 
Flow Controller ACEflow 2.0 (SolGelWay, France). The dip-coating apparatus described in Figure S 1. Silicon wafer of approximate size of $1.5 \mathrm{~cm}$ x $3 \mathrm{~cm}$ are directly plunged in the lipid solution, while gold substrates $(1 \mathrm{~cm} \mathrm{x} 1 \mathrm{~cm})$ are plunged after solidarization on the silicon wafer (at about $5 \mathrm{~mm}$ from the bottom).

Preparation of samples. G-C18:0 lipid is known to undergo a pH-driven micelle-to-lamellar phase transition: ${ }^{2,5}$ at $\mathrm{pH} 9$ and concentration below $5 \mathrm{mg} / \mathrm{mL}, \mathrm{G}-\mathrm{C} 18: 0$ assembles mainly into a micellar phase, while at $\mathrm{pH} 6$, it assembles into infinitely wide planar bilayers. We then employ two dipping strategies. In method 1 , we employ a lipid solution at $\mathrm{pH} 9$ while in method 2 the lipid solution is at $\mathrm{pH}$ 6. In both cases, temperature and relative humidity of the dipcoating chamber are respectively varied between 20 and $60^{\circ} \mathrm{C}$ and 5 and $95 \mathrm{RH} \%$.

Ellipsometry. Spectroscopic ellipsometry analyses are recorded with a UV-NIR (193-1690 nm) variable angle spectroscopic ellipsometer (VASE) M2000DI from J. A. Woollam Co., Inc. To increase the precision of the measurement, data are acquired at three different incident angles $\left(60^{\circ}, 65^{\circ}\right.$ and $\left.70^{\circ}\right)$ per location, close to the Brewster angles of silicon. The beam surface area is between $0.15 \mathrm{~cm}^{2}$ and $0.20 \mathrm{~cm}^{2}$, thus averaging the data over a broad surface. Each deposited lipid film is measured at three different locations. Data acquisition is performed with CompleteEASETM (Version 5.19, 2016) software by J. A. Woollam Co., Inc. Two substrates are used to deposit the lipid thin film, Si wafers and Au plates.

Ellipsometry data analysis. Ellipsometry is a technique, which measures the change of polarization states of an incident polarized beam after reflection from a sample. In particular, it provides access to the complex reflectance ratio, $\rho(\lambda)$ ( $\lambda$ is the wavelength of the incident light), which may be parametrized by the amplitude, $\Psi(\lambda)$ and the phase difference, $\Delta(\lambda)$, of the $p$ (parallel to the plane of incidence) and $s$ (perpendicular to the plane of incidence) polarized reflectivities, $r_{\mathrm{p}}$ and $r_{\mathrm{s}}$ according to $\rho=\tan \Psi \cdot \mathrm{e}^{\mathrm{i} \Lambda}=r_{\mathrm{p}} / r_{\mathrm{s}} \cdot{ }^{6}$ To maximize the difference in $r_{\mathrm{p}}$ and $r_{\mathrm{s}}$, experiments are performed close to the Brewster angle. Ellipsometry measures $\Psi(\lambda)$ and $\Delta(\lambda)$, which can be related to refractive index, RI, of the material and to its thickness, $T_{h}$, by adapted models.

Modelling and fitting of the $\Psi(\lambda)$ and $\Delta(\lambda)$ to recover the thickness, $T_{h}$, of the deposited thin film is done with the analysis tool of the CompleteEASETM (Version 5.19, 2016) software by J. A. Woollam Co., Inc. The detailed approach, some typical experimental and fitted $\Psi(\lambda)$ and $\Delta(\lambda)$ spectra and corresponding results of the fits are given in Figure $\mathrm{S} 2$ for the Si substrate 
and in Figure S 3 for the Au plate. Modelling is performed via the approach suggested in the CompleteEASETM data analysis manual (Ed. 2004-2011). In short, the Si substrate is modelled with a general oscillator (Gen-Osc) layer model (p. 131, data analysis manual), typical for absorbing thin films, while the native $\mathrm{SiO}_{2}$ oxide top layer is modelled with two layer models, a higher index interface layer (Intr_Jaw) and silica layer (SiO2_Jaw), respectively of thickness $1 \mathrm{~nm}$ and $0.52 \mathrm{~nm}$. Gen_Osc, Intr_Jaw and SiO2_Jaw are files containing the optical constants for each layer and available in the CompleteEASETM library (JAW stands for J. A. Woollam). They are the best-suited files to fit satisfactorily the $\Psi(\lambda)$ and $\Delta(\lambda)$ spectra of the reference, lipidfree, $\mathrm{Si}$ wafer (Figure $\mathrm{S} \mathrm{2a,b}$ and Table $\mathrm{S}$ 1). The Au plate is modelled with a $\mathrm{SiO}_{2}$ substrate (Glass_slide), a chrome layer of $T_{h}=5 \mathrm{~nm}(C r)$ and a gold layer of $T_{h}=200 \mathrm{~nm}\left(A u \_n k 1\right)$. The three layers correspond to the known composition of Au plates provided by the manufacturer. Glass_slide, $C r$ and $A u \_n k l$ are the best suited optical constants-containing files to obtain a good fit of the reference, lipid-free, Au plate (Figure S 3a,b and Table S 2).

The dip-coated lipid layer is modelled with a Cauchy model (Figure S 2a), classically employed for transparent thin films, which is the case for the lipids employed in the UV-VisNIR range. The refractive index, RI, of the lipid layer could be fixed. However, the actual values of RI are difficult to determine with precision for thin $(<10 \mathrm{~nm})$ films, due to uncertainty about the actual surface density of the film. At the same time, keeping RI as a variable under these conditions is not appropriate either, due to high chance to obtain physically unreal values. In this work, we make the following choice: we assumed to have a homogeneous coating and, for this reason, we systematically fit $\Psi(\lambda)$ and $\Delta(\lambda)$ of the lipid-coated supports using the lower and upper limits of RI values known for lipid bilayers, ${ }^{7,8}$ respectively $\mathrm{RI}=1.4$ and $\mathrm{RI}=1.7$, whereas the refractive index of glucose is also contained in this interval. In case of good quality fits, only those values of the thickness above $2 \mathrm{~nm}$ were considered to have a physical meaning and in agreement with a homogeneous mono, or multilayer, coating. The value of $2 \mathrm{~nm}$ is somewhat arbitrary but SAM of glycolipids bearing between one and three carbohydrate units were shown to have thickness (by ellipsometry) between 2.7 and $3.0 \mathrm{~nm} .{ }^{9,10}$ On the other hand, $2 \mathrm{~nm}$ is the lowest limit for a G-C18:0 interdigitated layer having a possible tilt angle of about $60^{\circ}$, a higher limit in self-assembled monolayers, ${ }^{11-14}$ with respect to the normal vector. Values of thickness below $2 \mathrm{~nm}$, although analytically correct, were not considered compatible with a homogeneous coating. The refractive index employed in the fit was probably not realistic, that is not compatible with a homogeneous dense coating, the underlying hypothesis of the Cauchy fitting model. The final thickness is taken to be as an average value with an error resulting from the 
extreme refractive indexes. On average, the experimental relative error on the thickness value per each sample is about $13 \%$.

Table S 1 and Table S 2 report, for selected samples, the fitted thickness at RI= 1.4 and $\mathrm{RI}=1.7$, the average value and the error. Table $\mathrm{S} 3$ provides the entire set of samples analyzed in this work by ellipsometry: the experimental conditions, the average value of the fitted thickness at $\mathrm{RI}=1.4$ and $\mathrm{RI}=1.7, T_{h}$, the standard deviation, $\sigma$, as well as the quality of the fit.

When the fit perfectly matches the experimental data within the imposed constraints, we consider it to be a good fit and the corresponding $T_{h}$ value to be reliable. Figure $\mathrm{S} 2 \mathrm{~d}$,e show typical examples of good quality fits giving reliable thickness values (samples 176 and 167 in Table S 1) on selected samples. However, it may happen that, even if the fit is of good quality, the thickness value assumes physically unreal values, below about $2 \mathrm{~nm}$ (samples 99-131 in Table S 3). It should be noted that the thickness of the G-C18:0 interdigitated layer can be calculated to be about $3.0 \mathrm{~nm}$ by applying the Tanford formula $(L=1.54+1.265 \times n, L$ being the length of the aliphatic chain and $n$ the number of methylene groups) ${ }^{15}$ to an effective $\mathrm{C} 16$ aliphatic chain and taking $8 \AA$ as the size of a single glucose molecule. ${ }^{16}$ This estimation is in agreement with the experimental values measured by SAXS in aqueous solution between $\mathrm{pH} 6$ and 7 and found to be in the order of $3.6 \mathrm{~nm}^{2,5}$ In this situation, the coating has either not occurred or the surface coverage is only partial. In other cases, fits are of poor quality, as shown in Figure S 2c, and the corresponding thickness (e.g., sample 203 in Table S 1) is generally unreliable. This often occurs for thick, poorly homogeneous, coatings.

Fluorescence microscopy. Fluorescence microscopy in reflection configuration is performed on substrates dip-coated in a lipid solution containing the Liss fluorophore. We use an Axio Observer D1, Carl Zeiss microscope, equipped with a CCD camera and a multi-wavelength light source. Samples are excited at 530-560 $\mathrm{nm}$ and the emission is detected between 571- 631 nm.

Atomic Force Microscopy (AFM). AFM images of dried surfaces were recorded using a MultiMode 8-HR AFM microscope from Bruker Instruments Inc. To avoid tip and sample damages, topographic images were taken in the QNM Air mode. SCANASYST-Air tips from Bruker (resonance frequency $70 \mathrm{kHz}$, force constant $0.4 \mathrm{~N} / \mathrm{m}$ ) have been used. Images were obtained at a constant speed of $1 \mathrm{~Hz}$ with a resolution of 512 lines and 512 pixels each. The raw data were processed using the imaging processing software NanoScope Analysis, mainly to correct the background slope between the tip and the surfaces. 
154 IR nanospectroscopy, AFMIR: Atomic Force Microscopy coupled to Infrared Spesctroscopy.

155 The principle of AFMIR is well described in several recent papers. ${ }^{17-21}$ To sum-up, an AFM is 156 coupled to an IR pulsed laser to perform chemical analysis of a sample at the nanoscale. The 157 technique allows performing IR analysis thanks to the tip in contact with the sample. It acquires 158 simultaneously topographical image and IR map at a specific absorption band as well as local 159 IR spectra. The technique is used in resonance-enhanced mode using a top-down illumination 160 (NanoIR2, Anasys Instruments, CA USA). The laser is a multi-chip quantum cascade laser 161 QCL (MIRCAT, Daylight solution, CA USA) ranging from $1510 \mathrm{~cm}^{-1}$ to $1920 \mathrm{~cm}^{-1}$. The laser 162 repetition rate ranges from $1 \mathrm{kHz}$ to $2 \mathrm{MHz}$ and is chosen to match the contact resonant 163 frequency of the AFM cantilever. A gold coated probe was used (MikroMasch : HQ:CSC38/Al164 BS-50 - spring constant $0.03 \mathrm{~N} / \mathrm{m}$ - resonance around $190 \mathrm{kHz}$ ). The spectra were collected 165 with $1 \mathrm{~cm}^{-1}$ spectral resolution. 


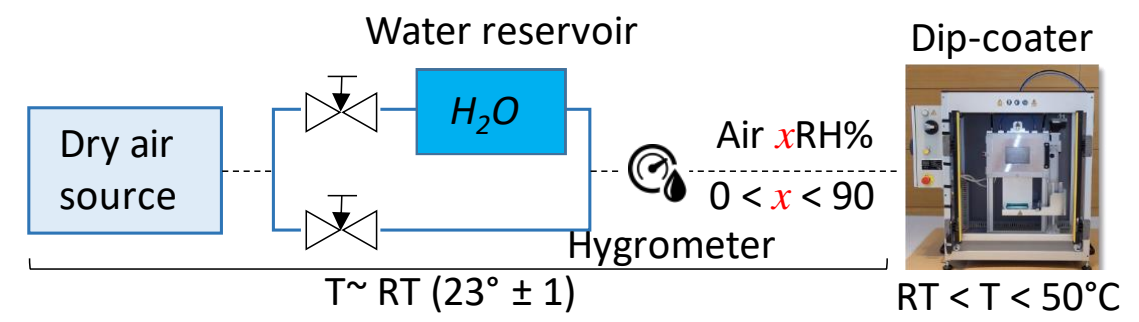

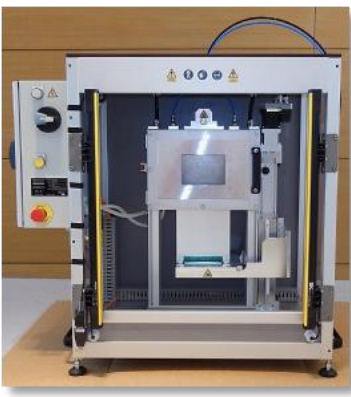

Dip-coater

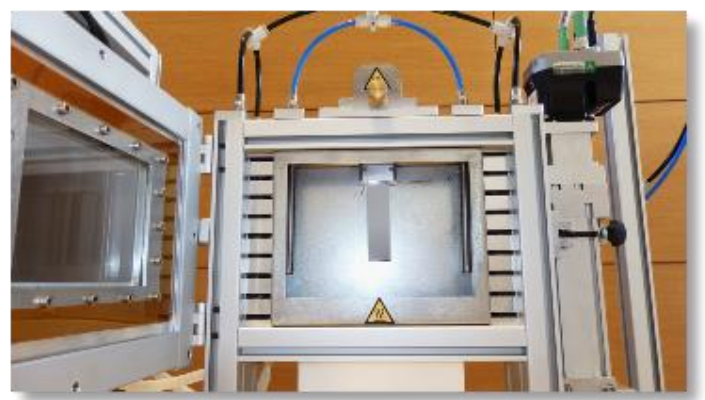

Temperature-stabilized closed dip-coating chamber

Figure S 1 - Scheme and images of the dip-coating system and apparatus 
Multilayer model to fit ellipsometry spectra with SILICON substrate

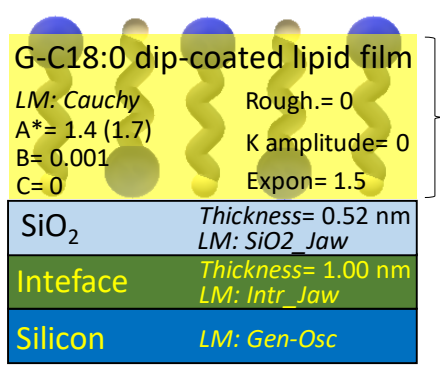

LM: Layer Model in Woollam EASE Sotware library

$T_{h} \quad *$ : A correponds to the refractive index, RI. Fits are performed with $\mathrm{RI}=1.4$ and $\mathrm{RI}=1.7$

Cauchy equation: $n(\lambda)=A+\frac{B}{\lambda^{2}}+\frac{C}{\lambda^{4}}$

Fitted parameter: lipid thickness, $T_{h}$

a)
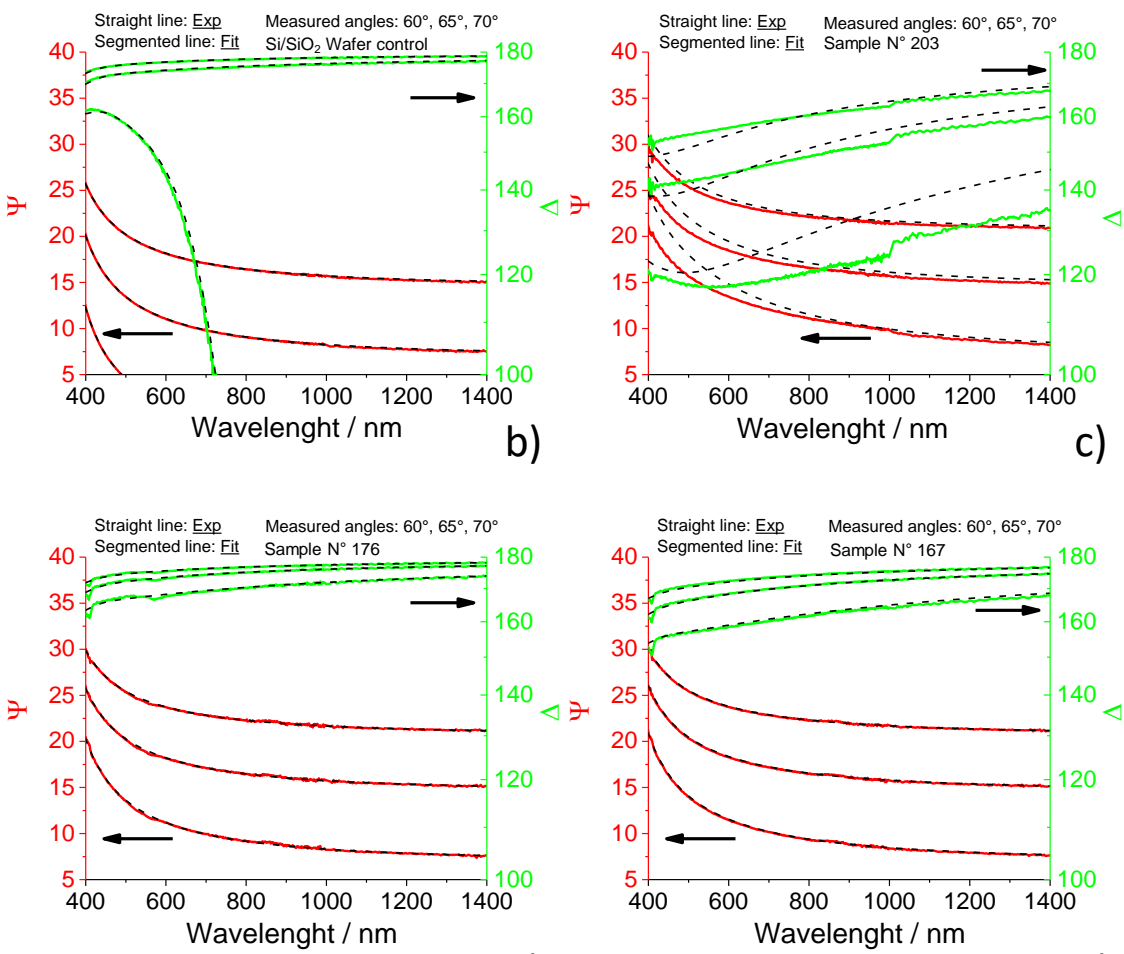

d)

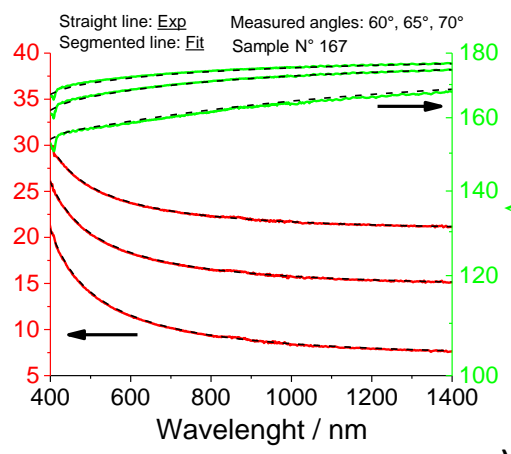

e)
Table S 1 - Fitted values of the thickness, $T_{h}$, and fit quality for Si wafer control and samples shown Figure

Figure S 2 - a) Scheme of multilayer model employed to fit the fit $\Psi(\lambda)$ and $\Delta(\lambda)$ spectra obtained by ellipsometry on samples coated on commercial silicon wafers. The typical fitted $\Psi(\lambda)$ and $\Delta(\lambda)$ spectra for selected samples are given for samples (Table S 3): b) commercial Si wafer control, c) $N^{\circ} 203, d$ ) $N^{\circ} 176, e$ ) $\mathbf{N}^{\circ} 167$. Typical good (d-e) and poor (c) quality fits are given on purpose.

S 2. $T_{h}$ is the average of the thickness values obtained with refractive index of 1.4 an 1.7 (lower and upper maximum reported for homogeneous, dense, lipid bilayers).

\begin{tabular}{|c|c|c|c|c|c|}
\hline Sample $\mathbf{N}^{\circ}$ & Substrate & $\boldsymbol{T}_{\boldsymbol{h}}(\mathbf{R I}=\mathbf{1 . 4})$ & $\boldsymbol{T}_{\boldsymbol{h}}(\mathbf{R I}=\mathbf{1 . 7})$ & Average $\boldsymbol{T}_{\boldsymbol{h}}$ & Fit quality \\
\hline $\begin{array}{c}\text { Silicon/SiO} \\
\text { control wafer }\end{array}$ & - & - & - & 0 & Good \\
\hline 203 & Silicon/ $\mathrm{SiO}_{2}$ & 20.66 & 14.14 & $10.40 \pm 3.01$ & Poor \\
\hline 176 & Silicon/ $\mathrm{SiO}_{2}$ & 2.25 & 1.70 & $1.98 \pm 0.39$ & Good \\
\hline 167 & Silicon/ $/ \mathrm{SiO}_{2}$ & 5.66 & 4.26 & $4.96 \pm 0.99$ & Good \\
\hline
\end{tabular}


Multilayer model to fit ellipsometry spectra with GOLD substrate

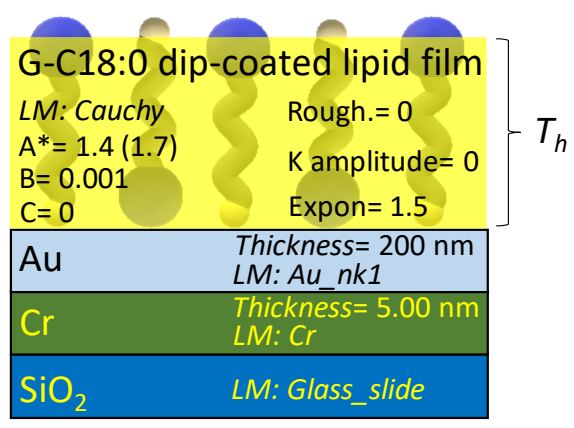

LM: Layer Model in Woollam EASE Sotware library

$T_{h} \quad *$ : A correponds to the refractive index, RI. Fits are performed with $\mathrm{Rl}=1.4$ and $\mathrm{RI}=1.7$

Cauchy equation: $n(\lambda)=A+\frac{B}{\lambda^{2}}+\frac{C}{\lambda^{4}}$

Fitted parameter: lipid thickness, $T_{h}$

a)
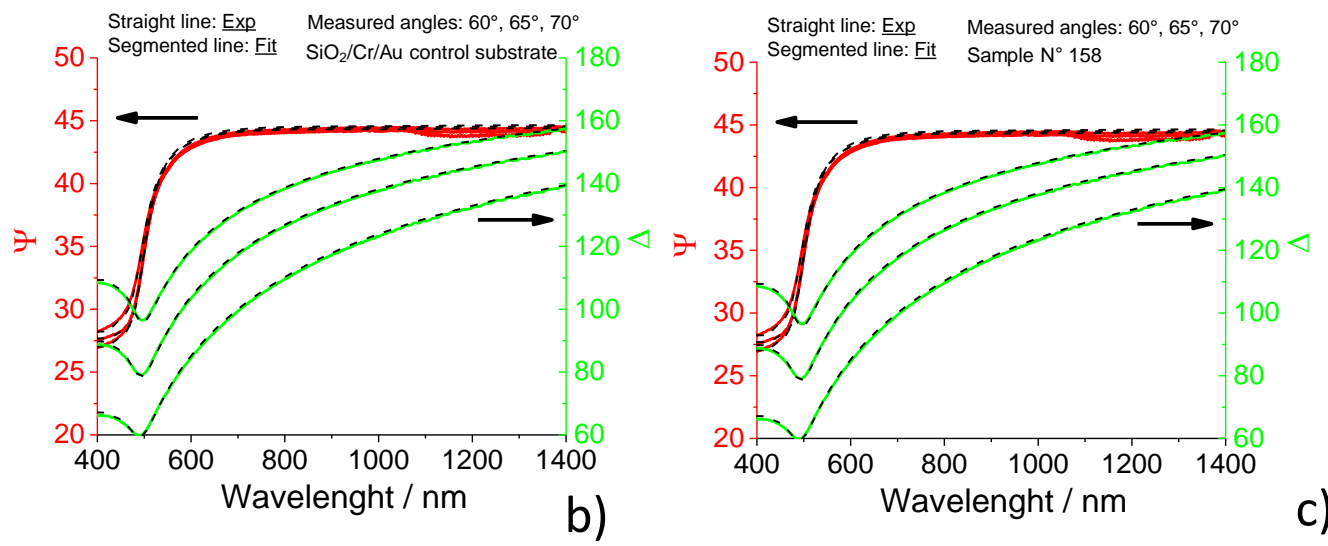

C)

179

Figure S 3 - a) Scheme of multilayer model employed to fit the fit $\Psi(\lambda)$ and $\Delta(\lambda)$ spectra obtained by ellipsometry on samples coated on commercial Au substrates. The typical fitted $\Psi(\lambda)$ and $\Delta(\lambda)$ spectra for selected samples are given for samples (Table S 3): b) commercial Au substrate control, c) $\mathbf{N}^{\circ} 158$.

Table S 2 - Fitted values of the thickness, $T_{h}$, and fit quality for Au substrate control and sample shown Figure $S$ 2. $T_{h}$ is the average of the thickness values obtained with refractive index of 1.4 an 1.7 (lower and upper maximum reported for homogeneous, dense, lipid bilayers).

\begin{tabular}{|c|c|c|c|c|c|}
\hline Sample N $^{\circ}$ & Substrate & $\boldsymbol{T}_{\boldsymbol{h}}(\mathbf{R I}=\mathbf{1 . 4})$ & $\boldsymbol{T}_{\boldsymbol{h}}(\mathbf{R I}=1.7)$ & Average $\boldsymbol{T}_{\boldsymbol{h}}$ & Fit quality \\
\hline $\mathrm{SiO}_{2} / \mathrm{Cr} / \mathrm{Au}$ control substrate & - & - & - & 0 & Good \\
\hline 158 & $\mathrm{SiO}_{2} / \mathrm{Cr} / \mathrm{Gold}$ & 13.4 & 9.08 & $11.24 \pm 3.05$ & Good \\
\hline
\end{tabular}



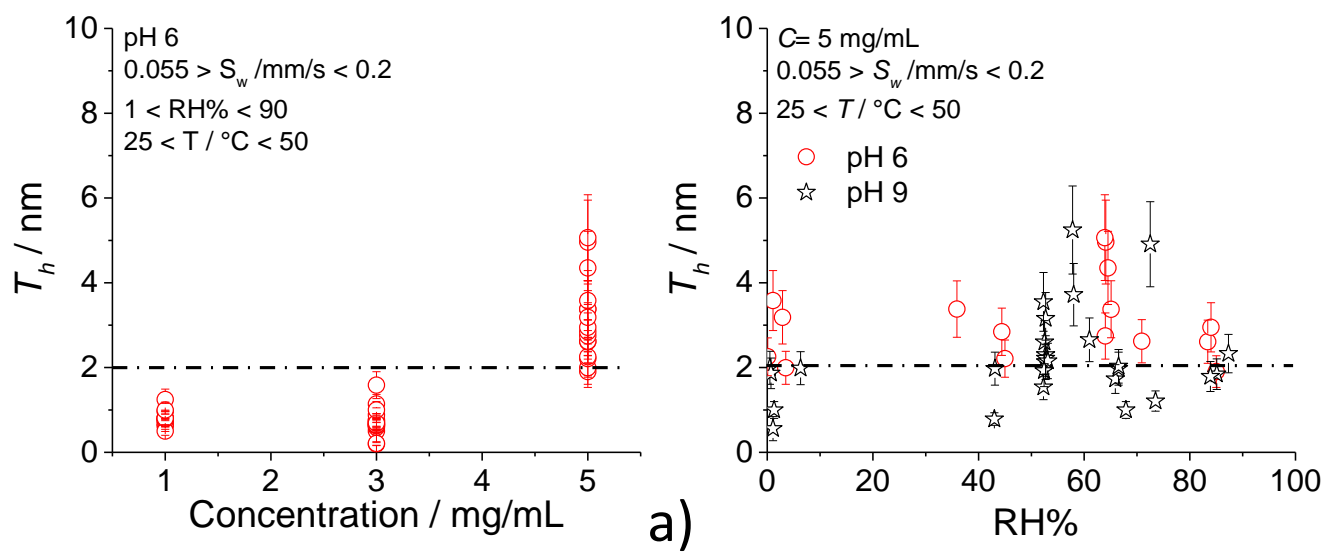

b)

Figure S $4-$ a) Evolution of $T_{h}$ as a function of the G-C18:0 lipid concentration in the parent solution. The specific conditions of $\mathbf{p H}, S_{w}, \mathbf{R H} \%$ and $T$ are given on the figures. The conditions for each plotted sample are given in Table $S$ 3. Samples $N^{\circ}$ are 99-139, 155-157, 159, 161, 163, 165, 167, 171. b) Evolution of $T_{h}$ as a function of the relative humidity in the dip-coating chamber. The specific conditions of solution concentration, $C, S_{w}$ and $T$ are given on the figures. Red circles and black stars respectively correspond to the $\mathrm{pH}$ of the parent solution. The conditions for each plotted sample are given in Table S 3. Sample $\mathbf{N}^{\circ}$ associated to red circles are: $155-157,159,161,163,165,167,171$, while sample $N^{\circ}$ for black stars are: 41 , 
Table S 3 - Full list of samples prepared in this work. The concentration, $C$, and $\mathrm{pH}$ are meant for the parent solution before dip-coating. Temperature, $T$, and relative humidity, $\mathrm{RH} \%$, are meant inside the dipcoating chamber, during dip-coating. $S_{w}$ : withdrawal speed, $T_{h}$ : thickness of the lipid film; $\sigma$ : standard deviation; Typical fit of poor and good quality are respectively given, as an example, in Figure $S$ 2c and Figure S 2d. Green lines: samples at pH 6 plotted in Figure 2 in the main text; Red lines: samples at pH 9 plotted in Figure 2 in the main text.

\begin{tabular}{|c|c|c|c|c|c|c|c|c|c|}
\hline $\begin{array}{c}\text { Sample } \\
\mathbf{N}^{\circ}\end{array}$ & Substrate & $\begin{array}{c}C / \\
\mathrm{mg} / \mathrm{mL}\end{array}$ & pH & $\begin{array}{l}\mathrm{T} / \\
{ }^{\circ} \mathrm{C}\end{array}$ & $\mathrm{RH} \%$ & $\begin{array}{c}S_{w} / \\
\mathbf{m m} / \mathbf{s}\end{array}$ & $\begin{array}{l}T_{h} / \\
\text { nm }\end{array}$ & $\begin{array}{l}\boldsymbol{\sigma} / \\
\mathbf{n m}\end{array}$ & Fit quality \\
\hline 11 & Si wafer & 5 & 9 & 27 & 56 & 1.000 & 19.03 & 5.65 & Poor \\
\hline 12 & Si wafer & 5 & 9 & 27 & 35 & 1.000 & 19.03 & 3.28 & Poor \\
\hline 18 & Si wafer & 5 & 9 & 27 & 56 & 1.000 & 25.85 & 5.79 & Poor \\
\hline 24 & Si wafer & 5 & 9 & 27 & 1 & 1.000 & 17.19 & 3.26 & Good \\
\hline 25 & Si wafer & 5 & 9 & 23 & 4 & 1.000 & 23.60 & 3.83 & Poor \\
\hline 26 & Si wafer & 5 & 9 & 23 & 3 & 1.000 & 13.64 & 2.68 & Good \\
\hline 27 & Si wafer & 5 & 9 & 23 & 2 & 1.000 & 0.20 & 0.04 & Good \\
\hline 41 & Si wafer & 5 & 9 & 34 & 58 & 0.075 & 3.72 & 0.74 & Good \\
\hline 42 & Si wafer & 5 & 9 & 33 & 58 & 0.050 & 5.25 & 1.04 & Good \\
\hline 50 & Si wafer & 5 & 9 & 22 & 53 & 0.100 & 2.16 & 0.42 & Good \\
\hline 54 & Si wafer & 5 & 9 & 23 & 53 & 0.075 & 2.14 & 0.42 & Good \\
\hline 55 & Si wafer & 5 & 9 & 24 & 53 & 0.050 & 2.22 & 0.43 & Good \\
\hline 56 & Si wafer & 5 & 9 & 23 & 53 & 0.025 & 2.30 & 0.45 & Good \\
\hline 57 & Si wafer & 5 & 9 & 23 & 52 & 0.125 & 1.93 & 0.37 & Good \\
\hline 58 & Si wafer & 5 & 9 & 21 & 53 & 0.150 & 3.16 & 0.62 & Good \\
\hline 59 & Si wafer & 5 & 9 & 21 & 53 & 0.175 & 2.60 & 0.51 & Good \\
\hline 60 & Si wafer & 5 & 9 & 21 & 52 & 0.113 & 1.54 & 0.30 & Good \\
\hline 61 & Si wafer & 5 & 9 & 21 & 52 & 0.200 & 3.55 & 0.69 & Good \\
\hline 62 & Si wafer & 5 & 9 & 21 & 84 & 0.125 & 1.79 & 0.35 & Good \\
\hline 63 & Si wafer & 5 & 9 & 21 & 85 & 0.100 & 1.85 & 0.36 & Good \\
\hline 64 & Si wafer & 5 & 9 & 21 & 87 & 0.113 & 2.33 & 0.45 & Good \\
\hline 69 & Si wafer & 5 & 9 & 21 & 1 & 0.100 & 1.00 & 0.20 & Good \\
\hline 99 & Si wafer & 1 & 6 & 25 & 41 & 0.117 & 1.00 & 0.19 & Good \\
\hline 100 & Si wafer & 1 & 6 & 25 & 41 & 0.055 & 0.67 & 0.13 & Good \\
\hline 101 & Si wafer & 1 & 6 & 25 & 41 & 0.100 & 0.97 & 0.19 & Good \\
\hline 102 & Si wafer & 1 & 6 & 25 & 41 & 0.112 & 0.50 & 0.10 & Good \\
\hline 103 & Si wafer & 1 & 6 & 25 & 89 & 0.117 & 0.80 & 0.16 & Good \\
\hline 104 & Si wafer & 1 & 6 & 25 & 89 & 0.055 & 0.62 & 0.13 & Good \\
\hline 105 & Si wafer & 1 & 6 & 25 & 75 & 0.055 & 1.25 & 0.25 & Good \\
\hline 106 & Si wafer & 1 & 6 & 25 & 73 & 0.100 & 0.82 & 0.16 & Good \\
\hline 107 & Si wafer & 1 & 6 & 25 & 72 & 1.000 & 0.69 & 0.14 & Good \\
\hline 108 & Si wafer & 1 & 6 & 25 & 2 & 0.117 & 0.81 & 0.16 & Good \\
\hline 109 & Si wafer & 1 & 6 & 25 & 1 & 0.055 & 0.76 & 0.15 & Good \\
\hline 110 & Si wafer & 1 & 6 & 25 & 1 & 0.100 & 0.76 & 0.15 & Good \\
\hline 114 & Si wafer & 3 & 6 & 42 & 1 & 0.055 & 1.14 & 0.23 & Good \\
\hline 115 & Si wafer & 3 & 6 & 42 & 52 & 0.055 & 0.77 & 0.15 & Good \\
\hline 116 & Si wafer & 3 & 6 & 45 & 52 & 0.117 & 1.00 & 0.20 & Good \\
\hline
\end{tabular}




\begin{tabular}{|c|c|c|c|c|c|c|c|c|c|}
\hline $\begin{array}{c}\text { Sample } \\
\mathbf{N}^{\circ}\end{array}$ & Substrate & \begin{tabular}{cc|}
$C /$ \\
$\mathrm{mg} / \mathrm{mL}$
\end{tabular} & pH & $\begin{array}{l}T / \\
{ }^{\circ} \mathrm{C} \\
\end{array}$ & $\mathrm{RH} \%$ & $\begin{array}{c}S_{w} / \\
\mathbf{m m} / \mathbf{s}\end{array}$ & $\begin{array}{l}T_{h} / \\
\text { nm } \\
\end{array}$ & $\begin{array}{l}\boldsymbol{\sigma} / \\
\mathbf{n m}\end{array}$ & Fit quality \\
\hline 117 & Si wafer & 3 & 6 & 44 & 52 & 0.100 & 0.50 & 0.10 & Good \\
\hline 118 & Si wafer & 3 & 6 & 46 & 2 & 0.117 & 0.69 & 0.14 & Good \\
\hline 119 & Si wafer & 3 & 6 & 44 & 1 & 0.100 & 0.68 & 0.13 & Good \\
\hline 120 & Si wafer & 3 & 6 & 46 & 82 & 0.055 & 0.74 & 0.14 & Good \\
\hline 121 & Si wafer & 3 & 6 & 49 & 73 & 0.100 & 0.72 & 0.14 & Good \\
\hline 122 & Si wafer & 3 & 6 & 47 & 78 & 0.117 & 0.65 & 0.12 & Good \\
\hline 123 & Si wafer & 3 & 6 & 26 & 48 & 0.055 & 0.20 & 0.04 & Good \\
\hline 124 & Si wafer & 3 & 6 & 26 & 48 & 0.117 & 0.21 & 0.04 & Good \\
\hline 126 & Si wafer & 3 & 6 & 25 & 85 & 0.055 & 0.67 & 0.13 & Good \\
\hline 127 & Si wafer & 3 & 6 & 25 & 84 & 0.117 & 0.63 & 0.15 & Good \\
\hline 128 & Si wafer & 3 & 6 & 25 & 79 & 0.100 & 0.88 & 0.17 & Good \\
\hline 130 & Si wafer & 3 & 6 & 25 & 4 & 0.117 & 0.64 & 0.13 & Good \\
\hline 131 & Si wafer & 3 & 6 & 25 & 4 & 0.100 & 0.59 & 0.11 & Good \\
\hline 132 & Si wafer & 5 & 6 & 25 & 4 & 0.055 & 2.00 & 0.39 & Good \\
\hline 133 & Si wafer & 5 & 6 & 25 & 3 & 0.117 & 3.19 & 0.63 & Good \\
\hline 134 & Si wafer & 5 & 6 & 25 & 0 & 0.100 & 2.26 & 0.45 & Good \\
\hline 135 & Si wafer & 5 & 6 & 25 & 85 & 0.055 & 1.91 & 0.37 & Good \\
\hline 136 & Si wafer & 5 & 6 & 24 & 84 & 0.117 & 2.95 & 0.58 & Good \\
\hline 137 & Si wafer & 5 & 6 & 24 & 83 & 0.100 & 2.61 & 0.51 & Good \\
\hline 138 & Si wafer & 5 & 6 & 24 & 45 & 0.055 & 2.21 & 0.44 & Good \\
\hline 139 & Si wafer & 5 & 6 & 24 & 44 & 0.117 & 2.85 & 0.56 & Good \\
\hline 142 & Si wafer & 5 & 9 & 24 & 43 & 0.117 & 1.98 & 0.39 & Good \\
\hline 143 & Si wafer & 5 & 9 & 24 & 43 & 0.117 & 0.79 & 0.15 & Good \\
\hline 145 & Si wafer & 5 & 9 & 26 & 6 & 0.100 & 1.99 & 0.39 & Good \\
\hline 146 & Si wafer & 5 & 9 & 26 & 73 & 0.100 & 4.91 & 1.00 & Average \\
\hline 147 & Si wafer & 5 & 9 & 25 & 74 & 0.100 & 1.21 & 0.24 & Good \\
\hline 148 & Si wafer & 5 & 9 & 25 & 1 & 0.100 & 0.56 & 0.28 & Good \\
\hline 149 & Si wafer & 5 & 9 & 25 & 1 & 0.100 & 1.87 & 0.36 & Good \\
\hline 150 & Si wafer & 5 & 9 & 25 & 1 & 0.100 & 2.00 & 0.39 & Good \\
\hline 151 & Si wafer & 5 & 9 & 25 & 70 & 0.100 & 32.82 & 8.43 & Poor \\
\hline 152 & Si wafer & 5 & 9 & 25 & 68 & 0.100 & 1.00 & 0.20 & Good \\
\hline 153 & Si wafer & 5 & 9 & 25 & 67 & 0.100 & 2.03 & 0.40 & Good \\
\hline 154 & Si wafer & 5 & 9 & 28 & 66 & 0.100 & 1.73 & 0.34 & Good \\
\hline 155 & Si wafer & 5 & 6 & 46 & 71 & 0.100 & 2.62 & 0.51 & Good \\
\hline 156 & Si wafer & 5 & 6 & 46 & 36 & 0.100 & 3.38 & 0.66 & Good \\
\hline 157 & Si wafer & 5 & 6 & 46 & 1 & 0.100 & 3.58 & 0.71 & Good \\
\hline 158 & $\mathrm{Au}$ & 5 & 6 & 29 & 67 & 0.100 & 11.24 & 3.05 & Good \\
\hline 159 & Si wafer & 5 & 6 & 29 & 64 & 0.100 & 2.75 & 0.54 & Good \\
\hline 160 & $\mathrm{Au}$ & 5 & 6 & 29 & 64 & 0.100 & 12.45 & 3.53 & Good \\
\hline 161 & Si wafer & 5 & 6 & 29 & 65 & 0.100 & 3.38 & 0.67 & Good \\
\hline 162 & $\mathrm{Au}$ & 5 & 6 & 29 & 64 & 0.100 & 30.28 & 6.83 & Average/Poor \\
\hline 163 & Si wafer & 5 & 6 & 29 & 65 & 0.100 & 4.35 & 0.86 & Good \\
\hline 164 & $\mathrm{Au}$ & 5 & 6 & 29 & 64 & 0.100 & 12.01 & 4.33 & Poor \\
\hline 165 & Si wafer & 5 & 6 & 29 & 64 & 0.100 & 5.07 & 1.01 & Good \\
\hline 166 & $\mathrm{Au}$ & 5 & 6 & 44 & 63 & 0.100 & 10.40 & 3.01 & Good/Average \\
\hline
\end{tabular}




\begin{tabular}{|c|c|c|c|c|c|c|c|c|c|}
\hline $\begin{array}{c}\text { Sample } \\
\mathbf{N}^{\circ}\end{array}$ & Substrate & $\begin{array}{c}C / \\
\mathrm{mg} / \mathrm{mL}\end{array}$ & pH & $\begin{array}{l}\mathrm{T} / \\
{ }^{\circ} \mathrm{C}\end{array}$ & RH\% & $\begin{array}{c}S_{w} / \\
\mathbf{m m} / \mathbf{s}\end{array}$ & $\begin{array}{l}T_{h} / \\
\text { nm }\end{array}$ & $\begin{array}{c}\boldsymbol{\sigma} / \\
\mathbf{n m}\end{array}$ & Fit quality \\
\hline 167 & Si wafer & 5 & 6 & 44 & 64 & 0.100 & 4.96 & 0.99 & Good \\
\hline 171 & Si wafer & 3 & 6 & 45 & 66 & 0.100 & 1.59 & 0.32 & Good \\
\hline 172 & $\mathrm{Au}$ & 3 & 6 & 44 & 67 & 0.100 & - & - & - \\
\hline 173 & Si wafer & 3 & 9 & 32 & 61 & 0.100 & - & - & - \\
\hline 174 & $\mathrm{Au}$ & 3 & 9 & 31 & 61 & 0.100 & 2.66 & 0.52 & Good \\
\hline 175 & $\mathrm{Au}$ & 3 & 9 & 31 & 69 & 0.100 & - & - & - \\
\hline 176 & Si wafer & 3 & 9 & 31 & 67 & 0.100 & 1.98 & 0.39 & Good \\
\hline 178 & Si wafer & 5 & 9 & 26 & 50 & 2.500 & 39.61 & 10.08 & Poor \\
\hline 179 & Si wafer & 5 & 9 & 26 & 50 & 5.000 & 43.19 & 10.69 & Poor \\
\hline 180 & Si wafer & 5 & 9 & 26 & 50 & 7.500 & 25.47 & 5.94 & Poor \\
\hline 181 & Si wafer & 5 & 9 & 26 & 49 & 10.000 & 9.14 & 1.92 & Poor \\
\hline 182 & Si wafer & 5 & 9 & 26 & 0 & 2.500 & 32.73 & 8.44 & Average \\
\hline 183 & Si wafer & 5 & 9 & 26 & 0 & 5.000 & 42.96 & 10.66 & Average \\
\hline 184 & Si wafer & 5 & 9 & 26 & 0 & 7.500 & 28.96 & 7.13 & Average \\
\hline 185 & Si wafer & 5 & 9 & 26 & 0 & 10.000 & 28.12 & 6.81 & Average \\
\hline 186 & Si wafer & 5 & 9 & 26 & 67 & 2.500 & 1.37 & 0.28 & Good \\
\hline 187 & Si wafer & 5 & 9 & 26 & 67 & 5.000 & 51.42 & 11.69 & Poor \\
\hline 188 & Si wafer & 5 & 9 & 26 & 68 & 7.500 & 33.21 & 8.54 & Poor \\
\hline 189 & Si wafer & 5 & 9 & 26 & 68 & 5.000 & 37.30 & 9.63 & Poor \\
\hline 191 & Si wafer & 5 & 6 & 26 & 63 & 5.000 & 13.95 & 2.82 & Poor \\
\hline 192 & Si wafer & 5 & 6 & 26 & 63 & 7.500 & 5.73 & 1.24 & Poor \\
\hline 193 & Si wafer & 5 & 6 & 26 & 62 & 10.000 & 14.14 & 2.86 & Poor \\
\hline 194 & Si wafer & 5 & 6 & 25 & 2 & 2.500 & 36.90 & 6.92 & Average \\
\hline 195 & Si wafer & 5 & 6 & 25 & 3 & 5.000 & - & - & Poor \\
\hline 196 & Si wafer & 5 & 6 & 25 & 0 & 7.500 & 54.79 & 9.98 & Poor \\
\hline 197 & Si wafer & 5 & 6 & 40 & 0 & 10.000 & - & - & Poor \\
\hline 198 & Si wafer & 5 & 6 & 43 & 2 & 2.500 & 11.46 & 1.92 & Average \\
\hline 199 & Si wafer & 5 & 6 & 44 & 2 & 5.000 & 17.05 & 2.91 & Poor \\
\hline 200 & Si wafer & 5 & 6 & 46 & 2 & 7.500 & 26.52 & 4.91 & Poor \\
\hline 201 & Si wafer & 5 & 6 & 46 & 1 & 10.000 & 28.28 & 5.29 & Poor \\
\hline 202 & Si wafer & 5 & 6 & 47 & 66 & 2.500 & - & - & Poor \\
\hline 203 & Si wafer & 5 & 6 & 48 & 79 & 5.000 & 18.40 & 3.20 & Poor \\
\hline 204 & Si wafer & 5 & 6 & 47 & 83 & 7.500 & 24.27 & 4.32 & Poor \\
\hline
\end{tabular}


Table S 4 - Surface roughness calculated from the $h(d)$ profiles ( $h$ is the height in $\mathbf{n m}$ and $d$ is the distance in $\mu m$ ) for samples corresponding to AFM images in Figure 4 in the main text (Sample list is given in Table $S 3)$ and to the bare control silicon substrate in Figure $S$ 5a. For sample 176 in profile Figure 4a) in the main text, only the $13<d(\mu \mathrm{m})<40$ region is considered to avoid the peak and valley artifacts. $R_{q}$ : root mean squared roughness; $R_{s k}$ : skewness; $R_{v}$ : valley roughness, lowest value of height; $R_{p}$ : peak roughness, highest value of height; $\Delta_{R p R v}$ : peak-to-valley roughness, largest height amplitude. In the formulas, $n$ is the number of height values in the $h(d)$ profiles.

\begin{tabular}{c|ccccc}
\multirow{2}{*}{ Sample N } & $\boldsymbol{R}_{\boldsymbol{q}} / \mathbf{n m}$ & $\begin{array}{c}\text { Skewness } \\
\left(\boldsymbol{R}_{\boldsymbol{s} \boldsymbol{k}}\right) / \mathbf{n m}\end{array}$ & $\boldsymbol{R}_{\boldsymbol{v}} / \mathbf{n m}$ & $\boldsymbol{R}_{\boldsymbol{p}} / \mathbf{n m}$ & $\boldsymbol{\Delta}_{\boldsymbol{R} \boldsymbol{p} \boldsymbol{v} \boldsymbol{v}}$ \\
\cline { 2 - 5 } & $\sqrt{\frac{1}{n} \sum_{i=1}^{n} h_{i}^{2}}$ & $\frac{1}{n R_{q}^{3} \sum_{i=1}^{n} h_{i}^{3}}$ & $\left|\min _{i} h_{i}\right|$ & $\left|\max _{i} h_{i}\right|$ & $R_{p}-R_{v}$ \\
\hline \multirow{2}{*}{171} & 0.58 & 0.44 & -0.87 & +1.14 & 2.01 \\
& 0.15 & -0.16 & -0.39 & +0.33 & 0.72 \\
Control: Si wafer & 0.19 & -0.70 & -0.44 & +0.28 & 0.72 \\
& 0.10 & 0.26 & -0.35 & +0.32 & 0.67 \\
& 0.18 & 0.28 & -0.57 & +0.74 & 1.31
\end{tabular}

The root mean squared $\left(R_{q}\right)$ roughness lies below $0.60 \mathrm{~nm}$ for all samples and practically below $0.2 \mathrm{~nm}$ for most of them, including the control. The skewness $\left(R_{s k}\right)$, which is indicative of the symmetry of the distribution, shows both slightly positive and negative asymmetry in the height distribution; however, this occurs in a random manner (e.g., positive and negative for the same sample) with $R_{\mathrm{sk}}$ being smaller than $|0.70| \mathrm{nm}$ and of the same order as for the Si wafer for most samples. The peak-to-valley height, $\Delta_{R p R v}$, between the highest peak $\left(R_{p}\right)$ and lowest valley $\left(R_{v}\right)$ is below $2 \mathrm{~nm}$ in the worst case scenario and actually comparable, and even smaller, than the control Si wafer $(1.31 \mathrm{~nm})$. 

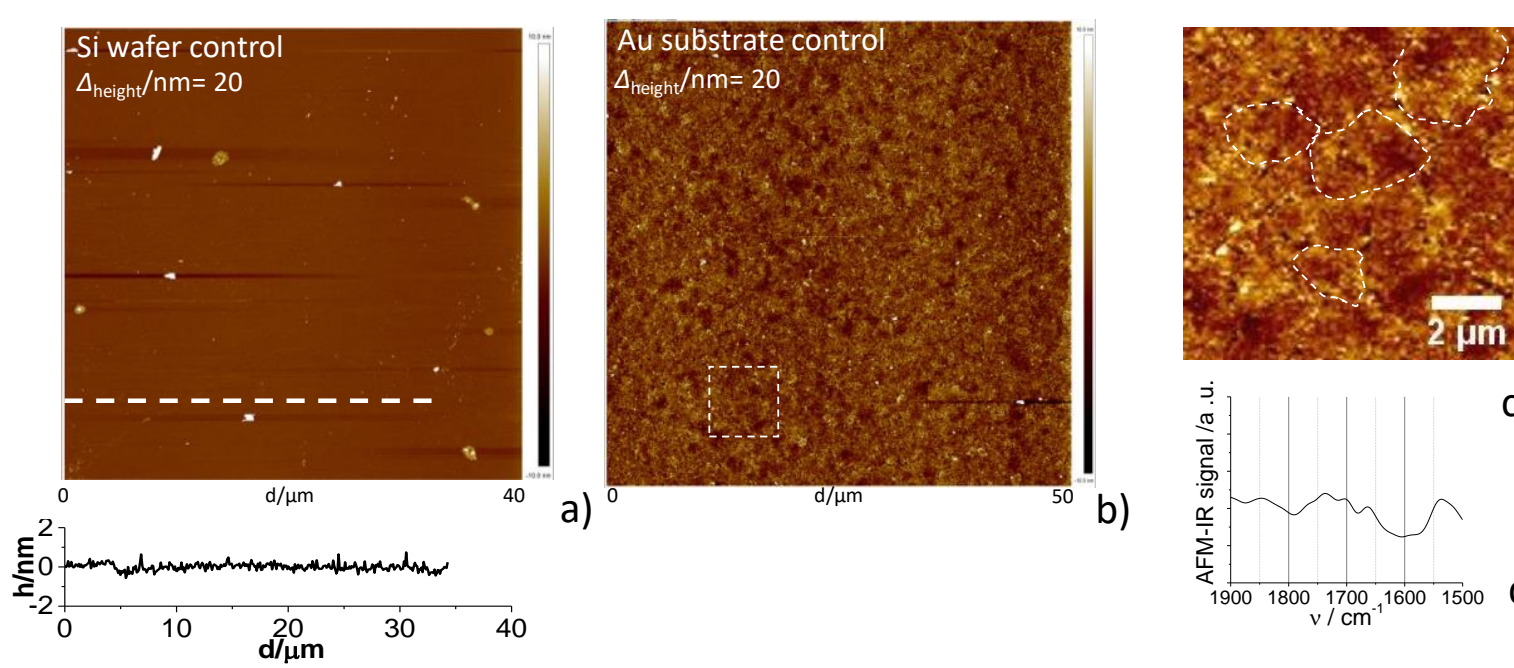

c)

Figure S 5 -a) AFM image and corresponding height - distance, $h(d)$, profile (white segmeted line) measured on a commercial Si wafer control substrate. b) Large-scale AFM image of the Au control substrate. c) Magnified AFM image of the Au control substrate showing the typical mosaic-like structure composed of Au (111) crystalline domains (white segmented lines). d) IR spectrum measured by AFMIR experiments on the Au substrate. The spectrum is the resul of 15 averaged spectra collected randomly on the corresponding AFM image in b). The gold substrate control displays no IR signal in the IR region between 1900 and 1500 $\mathbf{c m}^{-1}$. 

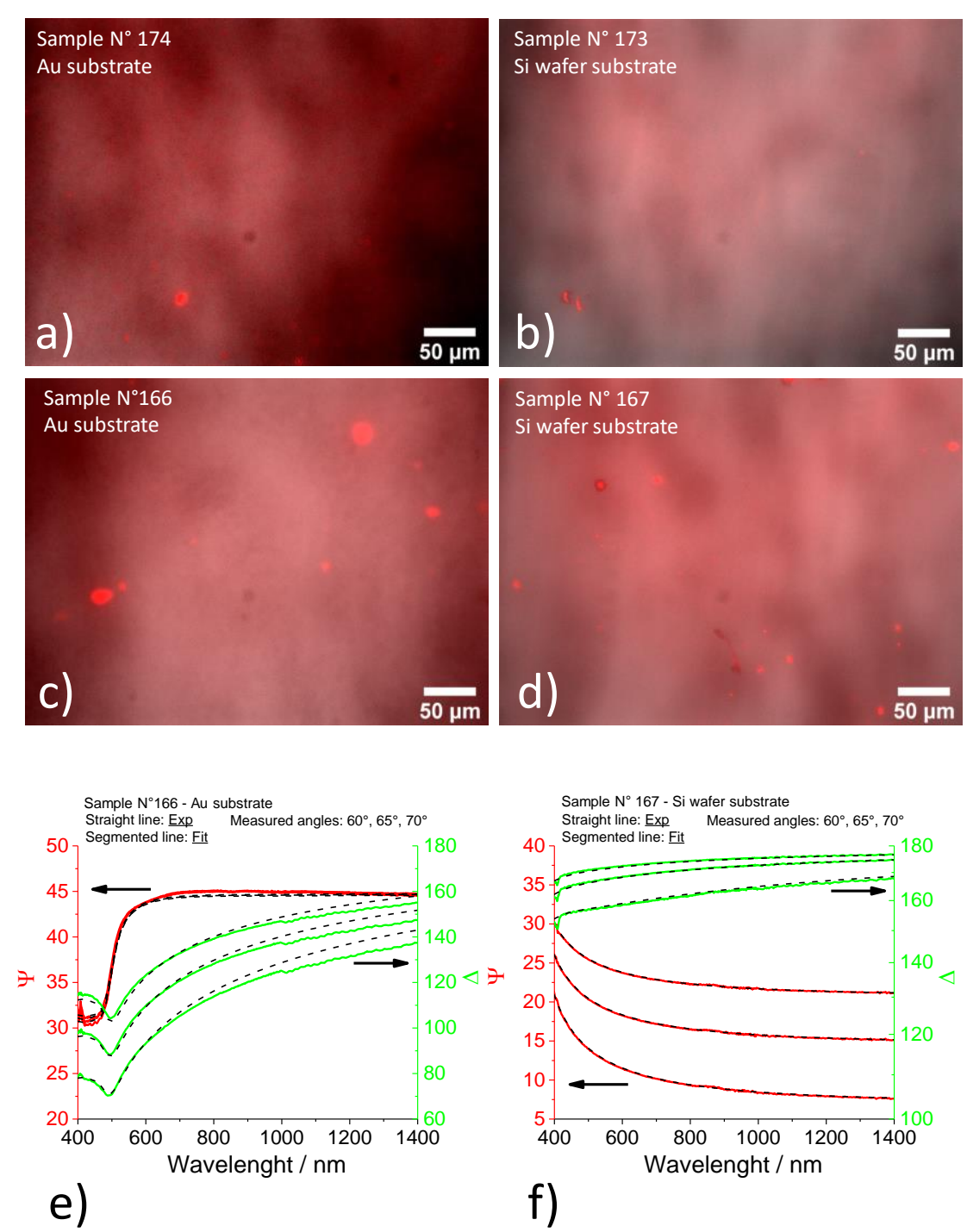

e)

f)

Figure S 6 - a-d) Fluorescence microscopy and e-f) ellipsometry experiments. Sample $N^{\circ} 174$ (a) and $\mathbf{N}^{\circ} 173$ are respectively prepared on gold and $\mathrm{Si}$ wafer substrates and they are dip-coated from the same parent solution employing the same conditions. Similarly, sample $N^{\circ} 166(c, e)$ and $N^{\circ} 167(d, f)$ are respectively prepared on gold and $\mathrm{Si}$ wafer substrates and they are dip-coated from the same parent solution employing the same conditions. Exact conditions for each samples are given in Table S 3.

Table $S 5$ - Fitted values of the thickness, $T_{h}$, and fit quality for samples $N^{\circ} 166$ and $N^{\circ} 167$, respectively prepared using Au and Si wafer substrates from the same G-C18:0 lipid solution and using the same dipcoating parameters (experimental details are in Table S 3). $T_{h}$ is the average of the thickness values obtained with refractive index of 1.4 an 1.7 (lower and upper maximum reported for homogeneous, dense, lipid bilayers).

\begin{tabular}{|c|c|c|c|c|c|}
\hline Sample N $^{\circ}$ & Substrate & $\boldsymbol{T}_{\boldsymbol{h}}(\mathbf{R I}=\mathbf{1 . 4})$ & $\boldsymbol{T}_{\boldsymbol{h}}(\mathbf{R I}=\mathbf{1 . 7})$ & Average $\boldsymbol{T}_{\boldsymbol{h}}$ & Fit quality \\
\hline 166 & $\mathrm{Au}$ & 12.52 & 8.27 & $10.40 \pm 3.01$ & Good \\
\hline 167 & Si wafer & 5.66 & 4.26 & $4.96 \pm 0.99$ & Good \\
\hline
\end{tabular}


If gold and silicon (intended as the native surface oxide layer for the latter) surfaces have comparable dispersive and electron acceptor (acidic) components of the surface energy, respectively in the order of $30 \mathrm{~mJ} / \mathrm{m}^{2}$ and $1 \mathrm{~mJ} / \mathrm{m}^{2}$, the electron donor (basic) component has a sensible difference of several tens of $\mathrm{mJ} / \mathrm{m}^{2}$, a fact which could influence the homogeneity, and even structure, of the G-C18:0 lipid coating between a gold and silicon surface, as shown before for sophorolipid glycolipids. ${ }^{22}$ For this reason, the surface homogeneity of the samples dipcoated on a gold substrate is preliminarily probed by ellipsometry and fluorescence microscopy, before the AFMIR analysis. Figure S 6 shows a set of microscopy and ellipsometry data recorded on both silicon and gold substrates dip-coated into the same initial solutions, whereas the modelling strategy of the gold substrates and the fit quality of the corresponding $\Psi(\lambda)$ and $\Delta(\lambda)$ profiles are discussed in the materials and method section and shown in Figure $S 3$. According to Figure S 6a-d, fluorescence microscopy does not demonstrate a sensible difference in terms of surface distribution of the fluorophore between the lipid-coated gold and silicon substrates: in all cases the images are characterized by a poorly-contrasted, homogeneously-distributed, fluorescence signal. In the case of gold substrates, the signal is superimposed to a mosaic-like structure at scales below $5 \mu \mathrm{m}$, and this is due to the typical polydisperse, cellular-like, structure of the surface (111) gold domains, of size between 1 and $5 \mu \mathrm{m}$, as shown by AFM on the control, lipid-free, gold substrates in Figure S 5b,c. The good matching between the fit and the experimental $\Psi(\lambda)$ and $\Delta(\lambda)$ profiles in the corresponding ellipsometry experiments, Figure S 6e,f, confirm the coating homogeneity on $\mathrm{Au}$ - and $\mathrm{Si}$-coated substrates on the cm-scale, although the average thickness seems to be slightly larger (about a factor 2) in the case of a gold substrate (Table S 5). These data show that replacing silicon with gold does not induce major changes in terms of homogeneity of the G-C18:0 lipid coating and for this reason, AFMIR can be reliably employed on lipid-coated gold substrates. 


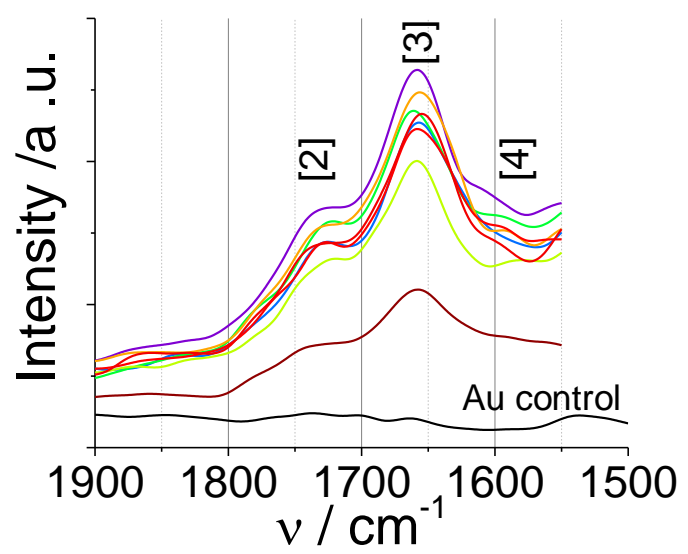

279 Figure S 7 - Non-normalized IR spectra corresponding to the AFMIR experiment performed on G-C18:0 280 lipid-coated gold substrates (Sample $N^{\circ} 175$, Table $S 3$ ) dipped at the optimal conditions of $S_{w}=0.1 \mathrm{~mm} / \mathrm{s}$.

281 Each spectrum is the average of 5 spectra, randomly collected on the AFM image presented in Figure 5a in 282 the main text. The Au control background signal is presented on Figure $\mathbf{S} 5 \mathrm{~d}$ and measured on a lipid-free 283 gold substrate (Figure S 5b,c). 

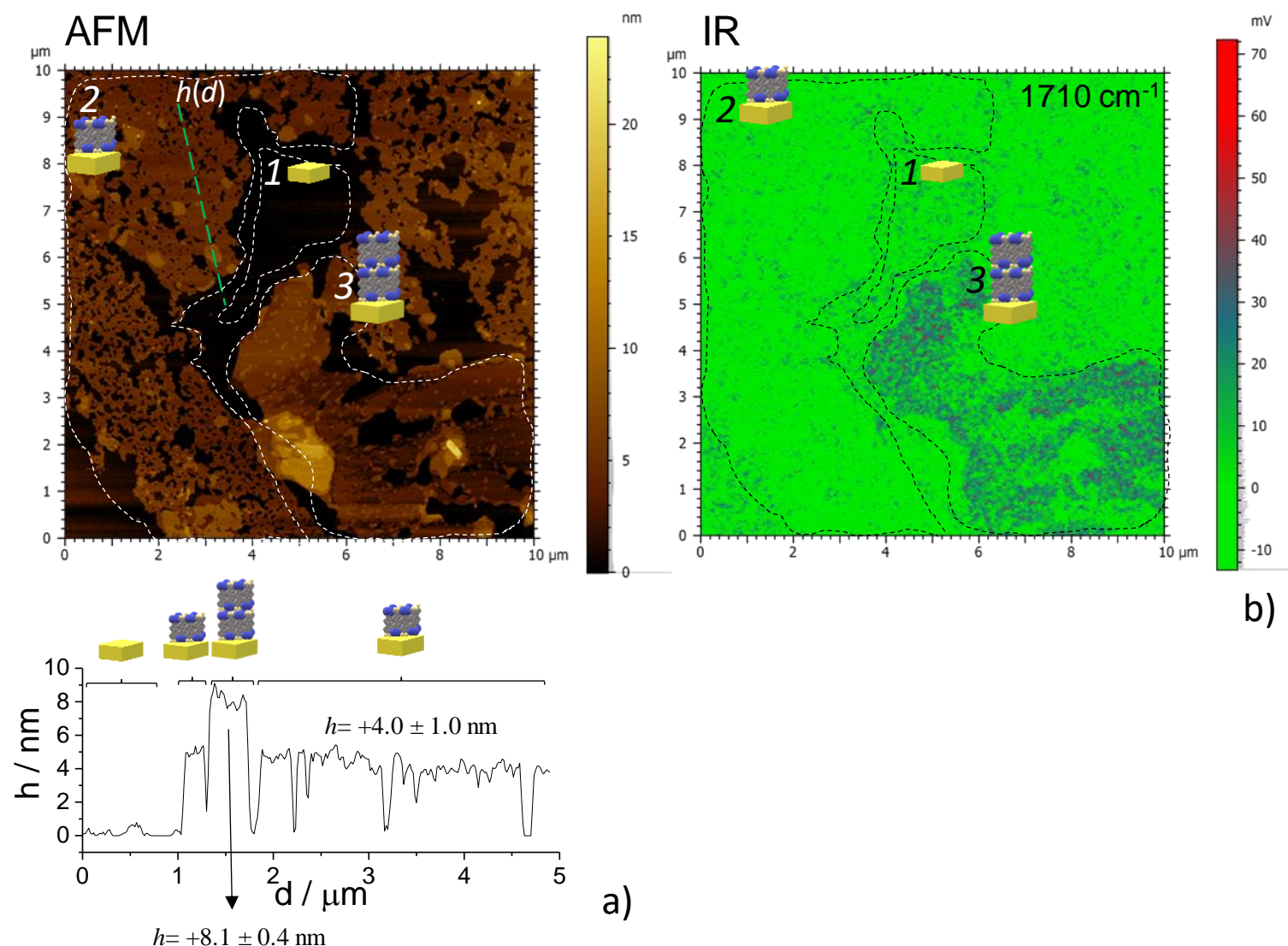

b)

Figure S 8 - Coupled AFMIR experiment performed on sample $\mathbf{N}^{\circ} 58$ (Table S 3) prepared on a Si wafer substrate. a) AFM image and corresponding thickness profile (green line), $h(d)$, measured along the white thick line. b) 2D IR cartography recorded at $1710 \mathrm{~cm}^{-1}$ and corresponding to the AFM image in a). Segmented regions labelled 1,2 and 3 in a) and b) correspond to the $\mathrm{Si}$ wafer substrate (1-labelled), singlelayer (2-labelled) and double-layer (3-labelled) G-C18:0 coating.

The 1-labelled region in the AFM image (Figure S 8a) identifies the Si wafer substrate $(h=0 \mathrm{~nm}$ ), while the 2-labelled region corresponds to a single-layered G-C18:0 coating, of average height over $3 \mu \mathrm{m}, h=+4.0 \pm 1.0 \mathrm{~nm}$, as indicated by the $h(d)$ profile in Figure $\mathrm{S} 8 \mathrm{a}$ relative to the continuous white line. The 3-labelled region, on the contrary, shows a brighter coating, corresponding to a doubled lipid layer with an average height, measured over $3 \mu \mathrm{m}$, of $h=+8.1 \pm 0.4 \mathrm{~nm}(h(d)$ profile in Figure S 8a). The corresponding 2D IR cartography in Figure S 8b interestingly shows that only a double lipid layer (2-labelled region) provides an IR signal intense enough to be detected. The lack of a signal corresponding to a single layer is explained by a lower amplification of the local electric field due to the use of Si wafer used for this sample instead of gold. 


\section{References}

1 K. M. J. Saerens, J. Zhang, L. Saey, I. N. A. Van Bogaert and W. Soetaert, Yeast, 2011, 28, 279-292.

N. Baccile, M. Selmane, P. Le Griel, S. Prévost, J. Perez, C. V. Stevens, E. Delbeke, S. Zibek, M. Guenther, W. Soetaert, I. N. A. Van Bogaert and S. Roelants, Langmuir, 2016, 32, 6343-6359.

A. I. Novaira, V. Avila, G. G. Montich and C. M. Previtali, J Photochem Photobiol B, $2001, \mathbf{6 0}, 25-31$.

M. Leonard-Latour, R. M. Morelis and P. R. Coulet, Langmuir, 1996, 12, 4797-4802.

N. Baccile, A.-S. Cuvier, S. Prévost, C. V Stevens, E. Delbeke, J. Berton, W. Soetaert, Ltd., 2007.

M. C. Howland, A. W. Szmodis, B. Sanii and A. N. Parikh, Biophys. J., 2007, 92, 1306-17.

S. Ohki, J. Theor. Biol., 1968, 19, 97-115.

T. Fyrner, H. H. Lee, A. Mangone, T. Ekblad, M. E. Pettitt, M. E. Callow, J. A.

C. Valotteau, C. Calers, S. Casale, J. Berton, C. V. Stevens, F. Babonneau, C. M. Pradier, V. Humblot and N. Baccile, ACS Appl. Mater. Interfaces, 2015, 7, 1808618095.

R. Arnold, A. Terfort and C. Wöll, Langmuir, 2001, 17, 4980-4989.

A. S. Duwez, U. Jonas and H. Klein, ChemPhysChem, 2003, 4, 1107-1111. Allg. Chemie, 2010, 636, 1506-1512.

Y. T. Tao and M. T. Lee, Thin Solid Films, 1994, 244, 810-814.

C. Tanford, The hydrophobic effect: Formation of micelles and biological membranes, Wiley-Interscience, 1973. 464.

A. Dazzi, R. Prazeres, F. Glotin and J. M. Ortega, Opt. Lett., 2005, 30, 2388. 
33920 A. Centrone, Annu. Rev. Anal. Chem., 2015, 8, 101-126.

34021 A. Dazzi and C. B. Prater, Chem. Rev., 2017, 117, 5146-5173.

34122 J. Peyre, A. Hamraoui, M. Faustini, V. Humblot and N. Baccile, Phys. Chem. Chem. Phys., 2017, 19, 15227-15238. 